\title{
Review Article \\ Reelin in the Years: Controlling Neuronal Migration and Maturation in the Mammalian Brain
}

\author{
Gabriella D'Arcangelo \\ Department of Cell Biology and Neuroscience, Rutgers, The State University of New Jersey, Piscataway, NJ 08854, USA \\ Correspondence should be addressed to Gabriella D’Arcangelo; darcangelo@dls.rutgers.edu
}

Received 18 August 2013; Accepted 15 October 2013; Published 5 January 2014

Academic Editor: Abdallah Hayar

Copyright (C) 2014 Gabriella D’Arcangelo. This is an open access article distributed under the Creative Commons Attribution License, which permits unrestricted use, distribution, and reproduction in any medium, provided the original work is properly cited.

\begin{abstract}
The extracellular protein Reelin was initially identified as an essential factor in the control of neuronal migration and layer formation in the developing mammalian brain. In the years following its discovery, however, it became clear that Reelin is a multifunctional protein that controls not only the positioning of neurons in the developing brain, but also their growth, maturation, and synaptic activity in the adult brain. In this review, we will highlight the major discoveries of the biological activities of Reelin and the underlying molecular mechanisms that affect the development and function of the mammalian brain, from embryonic ages to adulthood.
\end{abstract}

\section{The reeler Mouse and Reelin Gene Discovery}

Reelin was identified in 1995 as the gene disrupted in two mouse strains carrying the autosomal recessive mutation reeler, a transgenic and a spontaneous strain that originated in Edinburgh [1]. While a newly generated transgenic strain was instrumental in the cloning of the gene, the classic, spontaneous Edinburgh reeler mutant strain had been well known for decades to developmental neurobiologists for the distinct neurological phenotype observed in homozygous mice, which includes tremors, ataxia, cerebellar hypoplasia, and widespread disruption of cellular layers throughout the brain [2-10]. Upon cloning and mapping of the gene, it turned out that a large deletion in the Reelin gene had occurred in the Edinburgh strain, resulting in the complete loss of transcript expression [1]. Around the same time, a portion of the Reelin coding sequence was also identified in another spontaneous reeler strain that originated in Orleans [11]. In this strain, however, a truncated transcript predicted to encode a $\mathrm{C}$ terminal deletion mutant protein was stably expressed. To date, several additional reeler mouse mutant strains carrying mutations in the Reelin gene have been identified, all resulting in the loss of transcript expression. Like the original Edinburgh mutation (now called $\mathrm{B} 6 \mathrm{C} 3 \mathrm{Fe}$
ala-Relr $\left.{ }^{r l} / \mathrm{J}\right)$, these strains exhibit essentially the same reeler phenotype and are made commercially available from The Jackson Laboratory. As Reelin gene orthologs were identified in other vertebrate species, other reeler-like mutations were quickly characterized. In the rat, for example, two mutant strains, the Shaking Rat Kawasaki and the Komed Zucker Creeping rat, that exhibited a reeler-like phenotype were reported to carry Reelin gene mutation $[12,13]$. The human REELIN gene was also quickly cloned [14], and human subjects carrying REELIN mutations in homozygousity were identified few years later [15]. These patients exhibit lissencephaly with cerebellar hypoplasia (LCH), a phenotype that is very reminiscent of that observed in reeler mice.

One of the most intriguing aspects of the reeler phenotype is that many neuronal populations are born in normal numbers, at the right time and in the right place, but fail to reach the appropriate position and to form cellular layers in laminated cortical structures of the brain, such as the cerebral cortex, the hippocampus, or the cerebellum [6]. Additionally, failure of specific neuronal populations to reach appropriate locations and to assemble into distinct nuclei was reported in the brain stem and in the spinal cord $[5,16]$. These observations strongly suggested that the gene mutated in reeler mice had to be an essential regulator of neuronal migration 
and ultimately determines neuronal position within cortical structures and other anatomically distinct cellular aggregates of the central nervous system. Indeed, several studies have shown that Reelin plays important roles in the development of the spinal cord [16-18] and the retinal circuitry [19]. Here, we will discuss primarily its role in brain development and focus especially on recent advances related to the control of neuronal migration, which was the first recognized biological function of Reelin and, perhaps still to these days, its bestcharacterized activity. However, this is by no means its only function. In fact, it was noted early on that additional defects are present in the reeler mutant, including subtle connectivity abnormalities in the cerebellum [7] and fiber segregation abnormalities in the hippocampus [20, 21], suggesting that Reelin plays multiple roles in brain development.

How does Reelin control different aspects of brain development and function? Almost twenty years after its discovery, we still do not know everything to be known about this remarkable protein, but we have made tremendous progress in elucidating its structure, expression, and biochemical properties and ultimately in understanding how Reelin exerts its diverse functions, not only during embryonic and postnatal brain development, but also in the adult brain.

\section{The Reelin Gene}

Shortly after the identification of the Reelin coding sequence, the genomic organization of the mouse Reelin gene and its promoter region on chromosome 5 was unraveled [22]. This study revealed that the Reelin gene is very large and complex, containing 65 exons spanning approximately $450 \mathrm{~kb}$ of genomic DNA. The study also identified different Reelin transcripts generated by alternative splicing of a microexon although the significance of this splicing event remains obscure to these days. Furthermore, two different polyadenylation sites and a promoter region lacking canonical TATA and CAAT boxes, but containing putative recognition sites for transcription factors Sp1 and AP2, were defined. The promoter region of human REELIN gene was also cloned and characterized shortly thereafter, revealing the presence not only of Spl site, but also of binding sites for additional transcription factors, such as the cyclic AMP responsive element binding protein (CREB), $\mathrm{T}$ brain 1 (Tbr1), and paired homeobox 6 (Pax6) [23]. These and other followup studies led to the recognition that REELIN expression is heavily regulated by promoter methylation and that this epigenetic event may play an important role in controlling Reelin expression levels $[23,24]$. Since reduced expression of REELIN has been reported in patients with schizophrenia [25], bipolar disorder [26], and autism [27], these findings have potentially important implications for the treatment of these disorders. The intriguing association between REELIN expression and cognitive disorders, as well as the possible use of pharmacological agents that decrease methylation and restore normal levels of REELIN in these patients, has been extensively discussed in several review articles [2830]. Therefore, we will not address this topic here, except to underscore the importance of furthering our understanding of Reelin activities in processes that take place during brain development and beyond.

\section{The Reelin Protein}

The cloning of mouse Reelin coding sequence predicted that the encoded protein was likely to be large and secreted. Indeed, a full-length Reelin protein of approximately $385 \mathrm{kDA}$ was found to be secreted in the culture medium of wild type mouse neurons or clonal cells transfected with an expression vector containing the newly assembled coding sequence [31]. The secreted protein also was shown to be glycosylated. A remarkably similar protein was deduced from the sequence of the human REELIN cDNA, which resulted to be $388 \mathrm{kDA}$ in size and $94.2 \%$ identical to the mouse protein at the amino acid level [14]. However, since the sequence of Reelin did not extensively match other known sequences in the database, the cloning of Reelin revealed little about its biochemical function. The predicted protein had a modular structure composed of a series of unique repeats, flanked by distinct $\mathrm{N}$ - and $\mathrm{C}$-terminal regions. The $\mathrm{N}$-terminal region contains a signal peptide, which is required for secretion, a small region of similarity to the extracellular protein F-spondin, and an epitope region that is recognized by the CR-50 monoclonal antibody. This antibody was developed concurrently with the cloning of Reelin, based on the presence of an antigen expressed by Cajal-Retzius cells which was absent in the embryonic forebrain of reeler mice [32]. Upon cloning of Reelin, the CR-50 antibody was shown to recognize the Nterminal of the native protein [31]. This antibody turned out to be an excellent reagent to study not only the distribution of the Reelin protein in brain tissue slices, but also its function, since it interfered with many Reelin-induced cellular and molecular events [20,32-35]. Biochemical studies revealed that the interfering activity of the CR-50 antibody most likely lies in its ability to mask an N-terminal region of Reelin that is necessary for disulfide-linked homodimer formation [36]. The main body of the Reelin protein is composed of eight consecutive repeats, each composed of two subrepeats separated by a cysteine pattern commonly found in extracellular proteins, the EGF-like repeat [1]. The boundaries of these repeats have now been clearly defined, and the crystal structure of two central repeats 5 and 6 has been resolved in recent years [37]. The $\mathrm{C}$ terminal region of Reelin is highly conserved and contains a positively charged stretch of amino acids which appears to be important for optimal signaling [38]. Following the development of a battery of monoclonal antibodies [39], a biochemical analysis of the processing of Reelin became possible. It is now established that, after secretion in the extracellular environment, fulllength Reelin is rapidly cleaved by proteases at two specific sites, generating three major proteolytic fragments [40]. Among these, the central fragment composed of repeats 3 to 6 is the only one that appears to be necessary and sufficient to induce layer formation in a cortical slice culture assay [40]. This fragment also contains amino acid residues that are required for receptor binding and is sufficient to induce signal transduction, albeit to a reduced extent compared to 
the entire Reelin moiety [37, 40, 41]. Together, the data suggest that proteolytic processing is important in vivo to produce Reelin fragments, which can either diffuse away from the site of origin or assemble locally into large protein aggregates or homodimers capable of activating signal transduction to the full extent $[36,41,42]$.

\section{Reelin Expression during Brain Development}

In situ hybridization experiments gave an initial overview of Reelin expression in the mouse brain and spinal cord $[43,44]$. These studies also revealed that Reelin is expressed in many organs outside the central nervous system, during development and also in adult ages, suggesting that Reelin may be important not only for the initial cellular organization, but also for the stabilization and remodeling of these different tissues [43]. However, since only the brain was obviously disrupted in reeler mice, most studies of Reelin naturally focused on the development of this organ. Immunolabeling studies with the CR-50 antibody and double-labeling studies demonstrated that an early and transient neuronal population, the Cajal-Retzius cells, expresses high levels of Reelin during the embryonic development of forebrain structures [1, 20, 32, 44, 45]. These cells occupy the marginal zone of the cerebral cortex and hippocampus throughout embryonic development and die 1-2 weeks after birth, as neuronal migration and layer formation in these structures are completed. It is interesting to note that Cajal-Retzius cells had been described since the late 1800s, and their unique and complex morphology was carefully reconstructed, but it was not until the discovery of Reelin that the essential role of these cells in the control of neuronal migration during forebrain development was finally appreciated. In the embryonic cerebellum, Reelin is expressed by granule cell precursors in the external granule layer $[1,45,46]$. These cells eventually migrate inwardly to form the internal granule cell layer as the cerebellum continues to grow in size and becomes foliated at early postnatal ages. Thus, a similar scenario is present in all laminated embryonic cortical structures of the murine brain, where transient neurons express and secrete Reelin in superficial regions to promote neuronal migration and cellular layer formation in the cortical plate that is developing underneath them. This general pattern of expression is highly conserved in other rodents such as the rat $[47,48]$. In this species, Reelin is expressed not only by Cajal-Retzius cells but also by another cell population of the forebrain marginal zone, the subpial pyriform cells. With the development of new monoclonal antibodies that recognized human Reelin [39], more immunochemical studies became possible. These studies showed that, like in the rat, two major cell populations of Reelin-expressing cells are present in the marginal zone of the prenatal human neocortex: classic Cajal-Retzius and Cajal-Retzius-like cells [49]. The presence of additional Reelin-producing cells types in the embryonic marginal zone correlates with a more complex and protracted development of the neocortex in more cognitively competent species.

\section{Functions of Reelin during Brain Development}

What is the role of Reelin during early brain development? Clearly, the expression of Reelin by Cajal-Retzius and CajalRetzius-like cells in the embryonic forebrain is linked to the control of neuronal migration in the cortical plate. In the embryonic cerebral cortex, it specifically directs the radial migration and the formation of cellular layers by principal, excitatory cortical neurons born in the ventricular zone. The cellular and molecular mechanisms that underlie this critical biological function of Reelin in the embryonic forebrain will be discussed in detail below. Similar to the cerebral cortex, Reelin also directs the radial migration and layer formation of pyramidal neurons in the embryonic hippocampus proper. The essential function of Reelin in the establishment of cortical cellular layers is maintained postnatally in the dentate gyrus. In this structure, neurogenesis and granule neuron migration continues after birth and into adulthood. Thus, in this unique brain region, Reelin, produced by Cajal-Retzius cells in the outer molecular layer, continues to function as a major regulator of neuronal migration and cellular layer formation throughout life [50]. The importance of Reelin in the postnatal dentate gyrus as a positional clue is underscored by the finding that loss of Reelin is associated with granule cell dispersion in patients, as well as in animal models of temporal lobe epilepsy [51, 52]. This observation has potential clinical implications, since follow-up studies have shown that addition of recombinant Reelin can rescue granule cell dispersion, at least in animal models [53]. Recent studies further suggested that granule cell dispersion results from impaired Reelin processing and the consequent lack of secretion by Cajal-Retzius cells of the dentate gyrus and not from cell death or expression deficits, raising renewed interest in the identification of the proteases that carry out Reelin proteolytic cleavage [51]. In the cerebellum, Reelin produced by granule cells in the external granule layer is required for the radial migration of Purkinje cells, which are born in the cerebellar ventricular zone and form initially a plate and then a single-cell layer. This view stems from the extensive analysis of cerebellar development in reeler mice [7, 54-56], from Reelin gene and protein expression data [1, 46], and from functional studies in organotypic cultures [34]. Taken together, this body of work indicates that Reelin, expressed by transient cells in superficial layers, specifically regulates radial neuronal migration in all developing laminated brain structures.

In addition to cellular layer formation, Reelin produced by Cajal-Retzius cells has been shown to promote the initial growth of axonal and dendrite processes. The formation of hippocampal fiber layers was first recognized as a perinatal function of Reelin [57]. In the early postnatal hippocampus, Cajal-Retzius cells continue to secrete large amounts of Reelin in the stratum lacunosum moleculare (SLM) and the outer molecular layer (OML) of the dentate gyrus. These regions represent the main targets of the entorhinohippocampal pathway. Using an organotypic coculture system, investigators elegantly demonstrated that Reelin is not essential for targeting these axons to the SLM and OML, 
but it is required for their early growth and branching [20]. Furthermore, Cajal-Retzius-produced Reelin was shown to promote synaptogenesis by entorhinal afferents [58]. These studies implicated Reelin in axon maturation and indirectly implicated this protein in the formation of synaptic structures. However, the ability of Reelin to stimulate axon growth appears to be limited in time and place. Indeed, defects in the branching of entorhinohippocampal axons were only found in the developing, but not in the adult, reeler hippocampus [20]. Furthermore, no defects have been reported in other axonal pathways of reeler mice so far. Building on the early observation that dendrite growth and cellular orientation are abnormal in reeler [59-61], other studies implicated Reelin in the control of the growth of these cellular processes. Using a fluorescent transgene to facilitate visualization in vivo, the development of apical processes of dentate granule cells was found to be delayed in reeler mice [62]. Furthermore, using cultured immature hippocampal neurons of wild type and reeler mice, this study demonstrated that Reelin is directly required for normal dendritic elongation and branching. Altogether, these findings suggested that Reelin promotes the early growth of apical dendrites of hippocampal neurons, which grow toward the Cajal-Retzius-cell-containing layers at early postnatal ages. Similarly, in the developing cerebral cortex, Reelin signaling was shown to promote the outgrowth of apical dendrites originating from cortical neurons contacting Cajal-Retzius cells in the marginal zone $[63,64]$. In vitro studies largely supported in vivo observations and helped defining the molecular mechanisms underlying dendrite outgrowth by forebrain neurons [62, 65]. Recent studies further demonstrated that Reelin induces the extension of the Golgi apparatus in apical dendrites, thus stimulating dendrite growth and cell polarization [66]. However, as for axonal processes, the role of Reelin may be limited to promoting the initial dendrite outgrowth that occurs during development. This idea is supported by the observation that Reelin signaling is not required for the full maturation of pyramidal hippocampal neurons in long-term in vitro cultures [67].

Besides growth of cellular processes, synapse formation represents an important step in postnatal brain development, which occurs during the late phase of dendrite and axon maturation. During these later times, approximately corresponding to 2-3 weeks after birth in rodents, the expression of Reelin in the forebrain is no longer exclusively localized to superficial layers but is widespread throughout all cellular layers due to the gradual appearance of Reelin-expressing interneurons $[1,32,44,45,68,69]$. However, some CajalRetzius cells persist in the postnatal hippocampus and thus may play a role in later aspects of the development of this structure. Indeed, using fluorescence imaging techniques in vivo and in vitro, further studies demonstrated that Reelin promotes the development of dendritic spines [70]. This study specifically identified a defect in spine density in young adult heterozygous and homozygous reeler mice in vivo and in organotypic slice cultures in vitro, which was rescued by the addition of exogenous Reelin. However, as for the growth effect on hippocampal axonal and dendrites, spine density was only transiently impaired in young adult Reelin-deficient mice (less than 1 month old), was very slightly reduced at
2 months [71], and was no longer affected in adult animals older than 6 months of age.

Taken together, the evidence so far indicates that Reelin plays multiple roles in brain development: it plays a unique and major role in controlling radial neuronal migration in cortical structures during embryonic ages and also contributes to promoting the growth of some axonal projections in the hippocampus, apical dendrite development and synapse formation in forebrain cortical structures at postnatal ages. In the adult brain, it also modulates synaptic function and plasticity, as discussed later in this review (Figure 1).

\section{Cellular Targets of Reelin Signaling during Early Brain Development}

Decades of neuroanatomical analysis of the homozygous reeler mouse, which preceded the discovery of the Reelin gene, had set the stage for understanding the role of this protein in brain development. The reported widespread defects in cellular layer formation in all cortical structures implied that Reelin is essential for the migration of many neuronal populations, including most cortical and hippocampal neurons $[2,8,59,60,72-75]$. A careful examination of the progression of the anatomical defects during cerebellar development also indicated that the layer organization of Purkinje cells in the cerebellar cortex represented the step that was directly affected by the absence of Reelin [7, 54-56, 76]. Thus, the failure of granule cells to proliferate, which ultimately leads to the lack of foliation and cerebellar hypoplasia in reeler mice, was recognized as a secondary defect due to the malposition of Purkinje cells, which failed to enter the cerebellar cortex after leaving the ventricular zone and remained localized in a deep cerebellar mass. This insightful observation also suggested that Purkinje cells are the direct targets of Reelin and that Reelin primarily promotes the final steps in the radial migration of principal neurons in cortical structures. However, examination of the anatomical phenotype of reeler mice in other structures led to different interpretations. For example, in the reeler hippocampus, pyramidal neurons and dentate granule cells appeared to migrate past their normal position, leading to the hypothesis that Reelin represents a stop signal necessary to arrest radial migration rather than promoting it [57]. The cellular complexity of cerebral cortex made it even more difficult to predict, based on anatomical phenotype and expression data alone, the identity of the cellular targets of Reelin and its mechanism of action with regard to the control of radial migration. This determination required a deeper understanding of molecular mechanisms of Reelin activity on migration, which originated from advances in the wider field of brain development and the development of new genetic approaches that occurred over the course of two decades.

At the end of the 1900s, the prevailing view of neocortical development was that principal neurons, born in the ventricular zone, migrate radially into the cortical plate following the guidance of radial glial cells, which provide a scaffold for migration. Thus, a reasonable expectation around this time was that Reelin would affect the development or 


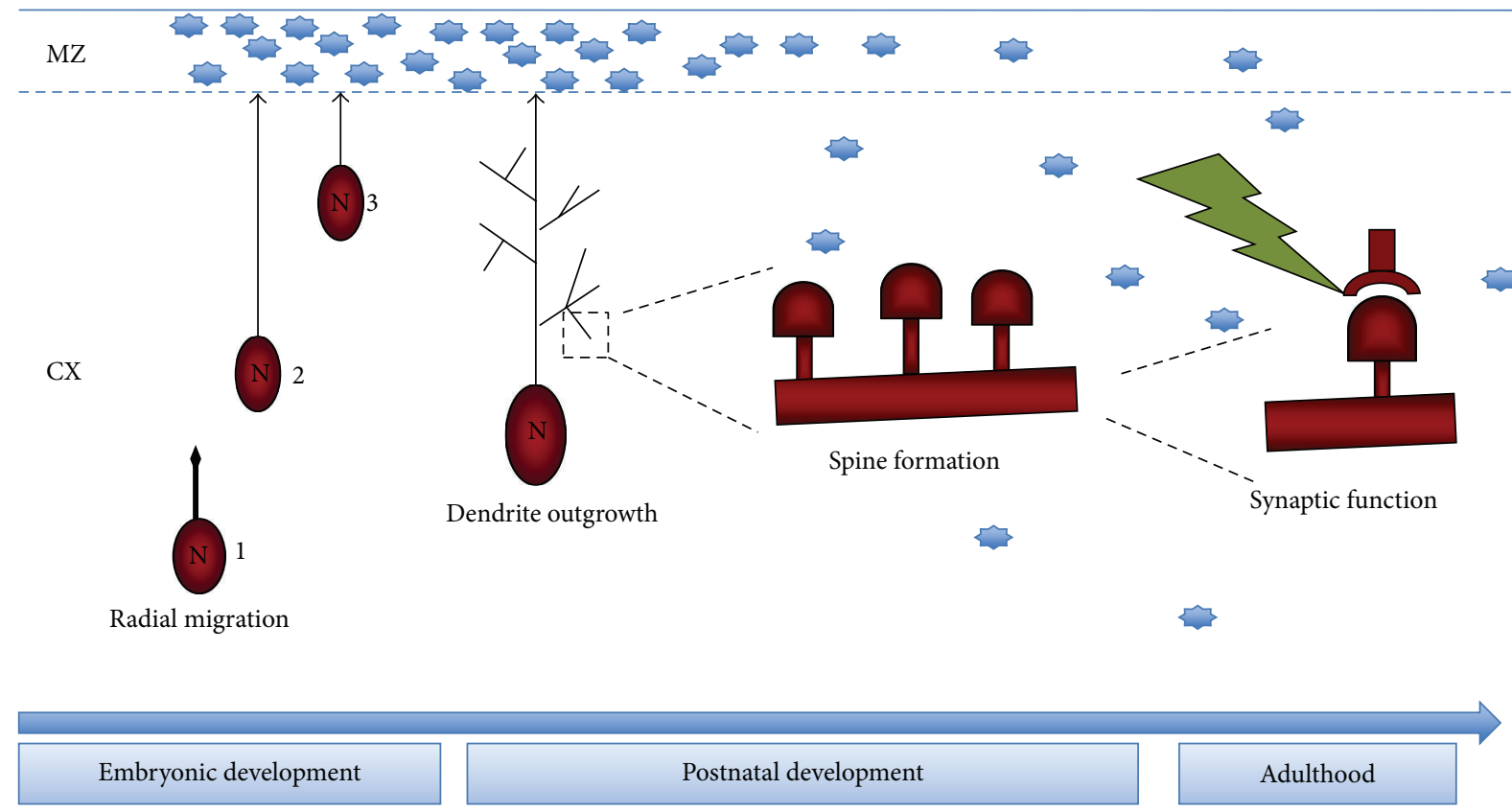

FIGURE 1: Schematic representation of the multiple activities of Reelin in the developing and adult forebrain. Blue octagons represent secreted Reelin molecules, and red ovals represent the cell bodies of principal forebrain neurons (N). During embryonic development, Reelin is mostly localized to the marginal zone (MZ) and directs radial migration by affecting multiple steps, such as radial orientation (1), attachment of the leading edge to the MZ (2), and somal translocation (3). During postnatal development, Reelin becomes expressed throughout cortical forebrain structures (CX), where it promotes mainly the growth of apical dendrites and spine formation. In the adult brain, Reelin modulates synaptic function and plasticity.

the integrity of radial glia scaffold and thus indirectly affect neuronal migration. Indeed, this scenario appears to be the predominant mechanism of action in at least one structure, the dentate gyrus of the hippocampus, where the radial glial scaffold is severely disrupted in reeler mutants [77]. In the reeler forebrain, some evidence of impaired radial glial cell development was also found [78]. However, based on the early observation that the CR-50 interfering antibody blocked neuronal aggregation in cortical explants lacking a true radial glia scaffold [32], the alternative hypothesis that Reelin may primarily affect principal cortical neurons directly, especially during the last phase of their migration inside the cortical plate, began to take hold [10]. Furthermore, new crucial discoveries in the field of cortical development provided a framework for this latter hypothesis. First, it became clear that radial glia cells are actually neural progenitor cells that give rise to many principal neurons of the neocortex $[79,80]$. Second, new imaging studies demonstrated that, in addition to glial-guided locomotion, neurons could also migrate independently of radial support, by somal translocation or a multipolar mechanism [81, 82]. However, the clear identification of the cellular targets of Reelin during radial migration required a better knowledge of the molecules necessary to transduce the signal.

In addition to its major function in the control of radial neuronal migration in cortical structures, Reelin was also shown to affect the migration of neuronal precursors in the rostromigratory stream [83]. These precursors engage in tangential chain migration from the subventricular zone of the cerebral cortex on route to the olfactory bulb. Reelin causes the detachment of these precursors from their substrate, thus disrupting their migration. Thus, neuronal precursors in the rostromigratory stream appear to be direct cellular targets of Reelin, even though Reelin exerts a negative effect on their migration.

\section{Molecular Mechanisms: The Discovery of the Dab1 Adaptor Protein}

The first essential transducer of the Reelin signal to be identified was the mammalian homolog of Drosophila Disabled1 (Dab1), an intracellular adaptor protein that, when phosphorylated on tyrosine residues, was capable of interacting with Src-homology (SH2) domains of Src-family kinases (SFKs) [84]. Dab1 contains a phosphotyrosine binding (PTB) domain, which also enables this adaptor protein to bind not only tyrosine-phosphorylated proteins, but also phosphoinosites and receptor internalization domains [85-87]. Spontaneous mutations in the Dabl gene were identified in scrambler and yotari, two independent lines of mutant mice that exhibited a phenotype remarkably similar to reeler [88-91]. Furthermore, an engineered Dab1 knockout mouse also exhibited the reeler-like phenotype [92]. The similarity between Dab1 and Reelin mutant mouse phenotypes strongly suggested that Dabl functioned downstream of Reelin in the same linear signaling pathway. In addition, biochemical studies revealed that recombinant Reelin rapidly induces 
the phosphorylation of Dab1 on multiple tyrosine residues in cultured cortical neurons [93-95]. This event is mediated mainly by Fyn and Src, two SFKs that are activated by Reelin $[96,97]$. Dabl phosphorylation on tyrosine residues is essential for signal transduction, since point mutations in these sites result in the appearance of a reeler-like phenotype in vivo [98]. Dab1 tyrosine phosphorylation is also coupled to its ubiquitination by the $\mathrm{Cbl}$ ligase and to its degradation by the proteasome system $[99,100]$. This degradation represents a mechanism for signal termination and explains why Dab1 protein levels are elevated in the brain of reeler as well as Fyn/Src double knockout mice $[89,101,102]$. Taken together, these findings indicate that Reelin promotes the activation of Dabl in target cells, but protein degradation mechanisms ensure that the signal is transient. This sequence of activation and shutoff may be crucial for the execution of multiple steps in neuronal migration. Indeed, different models have been proposed to explain how the Reelin function may change dynamically from a permissive, attractive clue during the initial phases of migration to a detachment from radial glia and thus a stop signal during later phases [103-106].

Expression studies indicated that Dab1 is expressed at high levels by principal neurons of the embryonic cerebral cortex and hippocampus and by Purkinje cells in the cerebellum, in a pattern that is largely complementary to that of Reelin [107, 108]. This pattern suggested that forebrain principal neurons and Purkinje cells are the direct targets of Reelin during migration and cellular layer formation. In the forebrain, however, Dab1 expression was also reported in radial glia cells [109], and the morphology of these cells was shown to be affected by Reelin [110], raising the possibility that Reelin may target both principal neurons and radial glia cells, to regulate migration and cellular layer formation.

\section{Cellular Mechanisms of Reelin-Dependent Neuronal Migration}

With the development of novel techniques that enabled investigators to manipulate gene expression in vivo and to observe neuronal migration in cultured organotypic slices, new functional studies became possible. Using the GFP-labeling retroviral and confocal imaging approach pioneered by the Kriegstein Lab to study cortical migration in rat cultures [80], investigators reported that Dabl mutant (scrambler) neurons maintain an increased adhesion to radial glia fibers which prevents them from reaching the upper cortical layers [111]. This view seemed to lend support to earlier hypotheses postulating that the reeler defect was essentially due to excessive cellular adhesion, leading to an inability of newborn neurons to bypass previously generated cohorts and causing a traffic jam along radial fibers $[9,112]$. This interpretation was challenged by later studies employing more sophisticated genetic tools [113]. Nevertheless, the first analysis of the migratory behavior of scrambler cortical neurons provided some important mechanistic insights into Reelin activity. Indeed, this study was the first to demonstrate that Dab1 is required to extend the leading processes of migrating neurons into the developing cortical plate. However, it did not identify the target cells directly affected by Reelin, since the scrambler cortical slices lacked Dabl in migrating cortical neurons as well as in radial glia. This issue was addressed in a following study, which utilized the newly developed technique of in utero electroporation [114] and RNA interference (RNAi) to suppress Dabl expression specifically in a subset of migrating neurons [64]. Dab1 knockdown neurons were found to be deficient in their ability to extend the leading process and to translocate their cell bodies into the upper cortical layers. In addition to pointing out a mode of migration that may be exquisitely affected by Dabl deficiency, this study also suggested that the apical processes of migrating neuron are essentially immature dendrites, and, in this context, Reelin stimulates the dendrite outgrowth, of neocortical pyramidal neurons, as it had been previously shown for hippocampal neurons [62]. Indeed, further studies demonstrated that Reelin controls neuronal orientation and polarized dendritic growth in the cortical plate as well as the developing cerebellum $[63,115,116]$. Together, these studies underscored the close functional link between cellular polarization, early dendrite outgrowth and neuronal migration. Despite these advances, many questions remained unanswered regarding the specific mode of migration affected by Reelin and Dab1 and the identity of the direct targets of Reelin during radial migration in the neocortex. These questions were finally answered through the development of a novel set of genetic tools, which enabled investigators to conditionally delete the Dabl gene in either early or late cortical neurons and examine their ability to undergo somal or glial-guide locomotion in cultured slices [113]. This study conclusively demonstrated that Reelin affects primarily somal translocation and that Dabl is required in migrating neurons to extend their apical process into the superficial areas of the neocortex, thus enabling both somal translocation of early-born neurons from the ventricular zone and also the terminal translocation of late-born neurons that initially move by glial-guided locomotion past cohorts of previously generated neurons. A following study demonstrated that Reelin in the marginal zone promotes the adhesion, stabilization, and branching of Dab1-expressing apical processes by a cell-matrix adhesion mechanism mediated by Integrin $\alpha 5 \beta 1$ [117]. However, this integrin may function in radial glia cells rather than in migrating neurons. Recently, another study documented heterotypic cell-cell interactions between migrating neurons and Cajal-Retzius cells, which are mediated by adhesion molecules nectin1 and nectin 3 and by Cadherin 2 [118]. CajalRetzius cells express nectin1, which binds nectin 3 on the cell surface of migrating neurons. Nectin3 and its associated effector afadin then mediate homophilic cell-cell adhesion via Cadherin 2 molecules, which are expressed by both cell types. These adhesion mechanisms allow for somal translocation to occur, bringing the cell bodies of migrating neurons just underneath the marginal zone, and explain why Reelin must be so strikingly localized to this zone during corticogenesis. They also reveal how Reelin (presumably in the form of a full-length protein, dimer, or insoluble multimer aggregate) conveys its short-range promigratory cue to neurons that come in contact with superficial layers via their apical process. But what about neurons that do not contact the marginal 
zone and are located in the deep regions of the intermediate zone during the development of the cortical plate? Most of these neurons exhibit an initial multipolar morphology and normally acquire a bipolar morphology just prior to engaging in radial migration. Are they responsive to Reelin, and how do they receive the signal? Earlier work using cortical slices demonstrated that soluble Reelin added to the culture medium was able to promote migration and layer formation, albeit not as neatly as in vivo [40]. This activity seemed unlikely to be spatially restricted to the marginal zone, but how would Reelin come in contact with these distant neurons in vivo? With the development of novel epitope-specific antibodies, it became possible to visualize Reelin fragments in brain sections [41]. These immunolabeling studies revealed that the central fragment of Reelin could reach the depth of the cortical plate, suggesting that the cleavage of the Reelin protein generates signaling molecules that may function at long range, away from the marginal zone. Consistently, a recent study revealed that Reelin affects the migratory behavior of neurons that are located deep into the developing cortical plate, by promoting the conversion from a multipolar to a bipolar morphology [119].

In summary, the data so far indicate that Reelin in the marginal zone promotes somal translocation of Dab1expressing principal cortical neurons directly from the ventricular zone, or terminal translocation from the developing cortical plate, and thus acts directly on migrating neurons as long as they make contact with the marginal zone through an apical process. This function may be induced by fulllength Reelin or fragments that assemble into oligomers to maximize signaling activity through the phosphorylation of Dab1. Reelin fragments may also diffuse into the depth of the cortical plate to promote the bipolar transformation and the oriented migration of Dabl-expressing neurons that do not contact the marginal zone. While it seems likely that these direct effects of Reelin on migrating cortical neurons do not require a radial glia scaffold, the possibility that Reelin also functions by affecting the stability and branching of the radial glia end feet cannot be excluded, particularly in structures such as the dentate gyrus where the radial scaffold could significantly contribute to the efficiency of migration.

\section{Dab1 Signaling in the Control of Reelin-Dependent Neuronal Migration}

In the section above, we discussed the crucial role of the adaptor protein Dab1 in Reelin-dependent neuronal migration. Here, we will discuss the molecular mechanisms linking Reelin to Dabl activation and the downstream events that link Dab1 to the execution of the migration function.

Early studies demonstrated that full-length Reelin or its central fragment alone induces the phosphorylation of Dab1 on specific tyrosine residues $[40,94,95]$. These phosphorylation events are mediated by the SFKs Fyn and Src, since they are blocked by the pharmacological inhibitor PP2 and by the genetic deletion of Fyn and Src genes [96, 101]. The appearance of a reeler-like phenotype in phosphomutant Dab1 mice [98], as well as double Fyn/Src knockout mice [101], further demonstrated that these tyrosine phosphorylation events are crucial for Reelin-induced neuronal migration and layer formation. Given the importance of this signaling event, considerable efforts have been devoted over the years to understand how Dabl phosphorylation is stimulated and what are the molecular consequences of this protein modification. However, signal transduction is often the result of a nonlinear series of intersecting events, and it soon became clear that Reelin signaling was not going to be an exception. Indeed, Reelin was found to stimulate Src phosphorylation (presumably reflecting an activation of multiple SFKs) in a manner that is dependent on the presence of Dabl $[97,120]$. Thus, it appears that a positive feedback mechanism potentiates SFK and Dabl activation in response to Reelin. SFK activation likely plays a major role in Reelin signal transduction. For example, it was shown to be required for the activation of other downstream events such as the activation of the PI3K by Reelin. The activation of PI3K was deduced from the induction of downstream events, such as the phosphorylation of Akt and the phosphorylation of GSK3 $\beta$ on an Akt-dependent site (Ser9) and from the ability of the PI3K pharmacological inhibitor LY294002 to block both of these events [121]. It was later demonstrated that Reelin also increases the levels of Akt phosphorylation on the Thr308 residue, a site which is directly phosphorylated by the PI3K-dependent kinase Pdk1 [71]. In addition, Dabl was found to interact directly with the PI3K regulatory subunit $\mathrm{p} 85 \alpha$ in response to Reelin stimulation [122]. Further downstream of Akt, other phosphorylation events were identified linking Reelin signaling to the mTOR pathway. The mTOR kinase participates in two complexes: mTORC1, which is primarily implicated in the control of protein translation and cell growth, and mTORC2, which is principally involved in the regulation of cytoskeletal dynamics [123]. Reelin was found to stimulate mTOR phosphorylation and to promote the mTORC1-dependent phosphorylation of p70S6K and the ribosomal protein S6 $[65,71]$. Thus, Reelin stimulates mTORC1 activity likely through SFK, PI3K, and Akt since p70S6K and S6 phosphorylation is blocked by the SFK inhibitor PP2 and by the PI3K inhibitor LY294002, in addition to the $\mathrm{mTORC1}$ inhibitor rapamycin [71]. However, it should be noted that, since biochemical studies identified mTORC2 as the complex that directly phosphorylates Akt on Ser473 [124] and Reelin stimulates this phosphorylation event, mTORC2 may also participate in Reelin signaling. The mechanism of activation of mTORC2 by many extracellular signals is not completely clear; however, SFK, PI3K, and Akt are also likely to mediate Reelin-induced mTORC2 activation, since Ser473 Akt phosphorylation is blocked by SFK and PI3K inhibitors. Despite the abundance of biochemical evidence, the biological significance of PI3K and Akt activation in Reelin signaling is not entirely clear. In vitro pharmacological studies using cultures cortical slices initially suggested that the activation of PI3K and Akt may be important for the control of neural migration during early brain development, while the activation of the mTOR pathway may be more relevant to postnatal functions of Reelin, such as the modulation of dendrite elongation [65]. 
However, a genetic requirement for PI3K and Akt in neuronal migration has not been demonstrated. Furthermore, the analysis of recent knockout models lacking PI3K modulators, such as the Pten phosphatase (a suppressor of PI3K) [125] or PIKE (an enhancer of PI3K) suggests that this kinase is likely to be primarily involved in the control of neuronal growth, dendritogenesis, and survival rather than migration or layer formation [126]. Finally, it should be noted that Akt phosphorylation defects have not been reported in the embryonic brain of reeler or Dabl mutant mice. Recent studies provided evidence that mTORC1 is involved in the NMDA-dependent rescue of synaptic plasticity and behavioral defects in juvenile reeler heterozygous mice [127]. Finally, basal levels of Akt phosphorylation were shown to be reduced in adult forebrain-specific conditional Dab1 knockout mice, which also exhibit plasticity and behavioral defects [128]. Together, these findings suggest that activation of the PI3K/Akt/mTOR pathway by Reelin may not play a crucial role in the early events leading to layer formation and corticogenesis but is likely to be involved in the postnatal control of neuronal maturation and synaptic plasticity.

Early efforts to identify potential downstream effectors of Dab1 in the control of migration pointed to components of the platelet activating factor (PAF) acetyl hydrolase $1 \mathrm{~b}$ (Pafahlb) complex. This complex functions as a phospholipase and catalyzes the PAF lipid through the activity of two catalytic $\alpha$ subunits. The complex also contains a regulatory subunit, Lis1, which is involved in neuronal migration [129] and human lissencephaly [130, 131]. Genetic interactions and biochemical experiments indicated that Reelin promotes the interaction between Dabl and Lisl and that the absence of these two proteins cooperated to increase the frequency of hydrocephalus [132]. Further studies also demonstrated that the catalytic subunit of Pafahlb $\alpha 2$ binds to Dabl and suppresses the hydrocephalus phenotype of Reelin/Lis double mutant mice $[133,134]$. However, Lis1 turned out to control many aspects of neurogenesis and neuronal migration through a mechanism that involves the coupling of the centrosome to the nucleus [135]. This mechanism appears to be independent of both the catalytic activity of the Pafahlb complex and Reelin. Furthermore, genetic ablation of the catalytic subunits of Pafahlb did not result in neuronal migration defects [133]. Thus, this complex does not appear to be involved in the control of migration or corticogenesis; however, it may play a role in as yet unidentified mechanisms that contribute to normal brain development by preventing the onset of hydrocephalus.

Other biochemical studies identified several molecules that bind Dab1 and thus may potentially function in Reelin signaling. These include proteins that affect the actin cytoskeleton, such as Nck $\beta$ [136] and N-WASP [100], proteins that modulate the activity of the Ras/Rap family of GTPbinding proteins, such as the GTPase activating protein (GAP) Dab2IP [137], and Crk family proteins [93, 138]. Recent RNA interference studies and knockout studies suggest that Dab2IP is required for neuronal migration in the neocortex [139] and for dendrite and synapse development in the cerebellum [140]. However, its direct involvement in Reelin signaling has not yet been established. Crk family proteins, on the other hand, have been shown to play a significant role in Reelin-dependent migration, likely by binding the GTP exchange factor (GEF) C3G, which then activates Rap1 [93]. Three members of this family, CrkI, Crk II, and CrkL, were shown to bind phospho-Dabl, and Reelin was shown to induce the phosphorylation of C3G and the activation of Rapl. This study suggested that the CrkL/C3G/Rapl pathway operates downstream of Dab1 in Reelin-stimulated neurons. However, CrkI and II, but not CrkL, were also shown to promote Dabl phosphorylation in an SFK-dependent manner, suggesting a more complex signaling mechanism [138]. The biological relevance of Crk family proteins in neuronal migration was demonstrated in vivo by the conditional double knockout of Crk and CrkL in neural progenitor cells. In a situation analogous to that of Fyn and Src, single Crk or CrkL mutant mice displayed mild neuroanatomical phenotypes, but double Crk/CrkL mutant mice displayed a reeler-like phenotype [141]. The absence of Crk and CrkL did not affect Dabl phosphorylation but, surprisingly, hindered the ability of Reelin to phosphorylate not only C3G, but also Akt on Ser473. Because this site is a target of mTORC2, these findings raise the possibility that Crks transduce Reelin signaling downstream to Rap1 as well as mTORC2.

The role of Rapl in Reelin signaling and radial migration was further explored in multiple in vivo studies. In one study, Rap1 was shown to regulate the expression of cell adhesion molecules of the Cadherin family in migrating neurons, an event that is required for glia-independent migration [113]. Specifically, in this study, it was proposed that Rap1 promotes Cadherin expression, which in turn favors the extension and attachment of leading processes of migrating neurons and enables terminal translocation near the upper cortical plate. In a second study, Rap1 was shown to regulate the membrane localization of $\mathrm{N}$ Cadherin [119]. This event was linked specifically to the acquisition of proper cellular orientation, which is also required for glia-independent neuronal migration, but occurs in the deeper regions of the developing cortical plate. Building on these observations, recent studies further investigated the role of the Crk/C3G/Rapl pathway in Reelindependent migration and provided a comprehensive view of its molecular mechanisms [117, 118]. This work suggested that Rap1 has a dual function in migration. In deep regions of the cortical plate, Rapl functions through $\mathrm{N}$ Cadherins to orient cell bodies and enable entry into the cortical plate, but this activity may not be stimulated by C3G. Near the upper cortical plate, Reelin strongly activates C3G and Rap1, and this in turn leads to the activation of $\alpha 5 \beta 1$ integrins, which mediate the attachment of apical processes to fibronectin in the marginal zone, and the recruitment of cell adhesion molecules such as nectins and Cadherin 2, which mediate cell-cell interactions in the marginal zone. Together, these secreted and contactdependent mechanisms enable terminal translocation and the completion of radial migration near the Reelin-rich marginal zone. 


\section{Reelin Receptors and the Control of Neuronal Migration}

The body of work discussed above described in considerable detail the cellular and molecular mechanisms of neuronal migration which operate immediately upstream and downstream of Dabl during Reelin signal transduction. This section will address the receptor activation mechanisms leading to Dabl recruitment at the plasma membrane. What are the Reelin receptors, and how do they cause SFK activation and Dabl phosphorylation?

Based on extensive genetic and biochemical studies, two high-affinity Reelin receptors have been identified and shown to play a major role in Reelin signaling. They are the apolipoprotein E receptor 2 (ApoER2) and the very-lowdensity lipoprotein receptor (VLDLR) [33, 142]. These two receptors are members of the lipoprotein receptor superfamily [143], and their involvement in Reelin signaling was first suggested by the observation that double Apoer2/Vldlr knockout mice exhibit a reeler-like neuroanatomic phenotype [102]. Single knockout mice displayed a milder layer phenotype, suggesting that they have partially overlapping functions in mediating the activity of Reelin on neuronal migration. Biochemical experiments in vivo and in vitro demonstrated that ApoER2 and VLDLR are each capable of binding Reelin with similar affinity $[33,142,144]$. Like all members of the lipoprotein receptor superfamily, ApoER2 and VLDLR can also bind lipoproteins and other extracellular ligands with lower affinity. Upon binding, these receptors internalize their ligand, including Reelin, a process that requires the NPxY motif, an internalization domain present on the cytoplasmic tail of the receptors. The receptors also bind Dabl on their cytoplasmic tail near their NPxY motif $[86,145]$. On the Dab1 side, binding to the receptors is mediated by the pleckstrin homology/phosphotyrosine binding domain (PH/PTB) $[87,145,146]$. ApoER2 and VLDLR actively traffic between the plasma membrane and the endosomes, and their translocation to the plasma membrane is facilitated by Dabl binding [146]. Upon Reelin binding, the receptors cluster and internalize [147], thereby causing the activation of Fyn and Src, which then phosphorylate Dabl and initiate downstream signaling events crucial for migration. Despite their partially redundant function, there are differences between ApoER2 and VLDLR signaling. Some of the differences can be attributed to relative receptor expression. For example, VLDLR is more highly expressed in the Purkinje cells of the cerebellum, and single VLDLR knockout mice exhibit defects in this structure, whereas ApoER2 is preferentially expressed in cortical and hippocampal neurons, correlating with defects in forebrain structures of single ApoER2 knock out mice [102]. However, the two receptors can bind distinct signaling proteins, in addition to Dab1. Indeed, VLDLR, but not ApoER2, has been found to bind subunits of the Pafahlb complex [148], whereas ApoER2, but not VLDLR, can bind JNK and activate the p38MAP kinase pathway [149]. However, it is not clear whether these unique interactions participate in the control of neuronal migration. Both ApoER2 and VLDLR bind Reelin through a similar extracellular domain that contains a conserved lysine residue [37]. It is thought that the strongest signal activation is achieved when the receptors bind multimeric aggregates of full-length Reelin, presumably leading to massive receptor clustering and SFK activation [42]. However, it has been shown that ApoER2 and VLDLR can also bind a central fragment of Reelin that is generated by proteolytic cleavage [40]. Functional studies demonstrated that binding of this fragment is sufficient to induce Dab1 phosphorylation and lead to layer formation in cultured cortical slides. These findings raised the question of whether Reelin cleavage is an event that dampens activity by reducing the levels of the more active full-length protein or enables activity by releasing the active central fragment from a precursor fulllength protein. This question has not yet been resolved and awaits the identification of the specific sites of cleavage, as well as the identification of the proteases responsible for Reelin cleavage. In the meantime, the fact that $\mathrm{N}$ - and C-terminal Reelin fragments are generated by cleavage and that they do not bind ApoER2 and VLDLR raised the possibility that other receptors or coreceptors may participate in Reelin signaling and contribute to migration control.

Some of the earliest candidates as alternative Reelin receptors were integrins. Integrins $\alpha 3 / \beta 1$ and $\alpha 5 / \beta 1$ in particular were implicated in Reelin signaling by binding experiments [150]. However, this finding has not been replicated by others, and the analysis of knockout mice lacking several integrin subunits suggested that, while these proteins contribute to migration and layer formation, they may not be directly required for Reelin-dependent migration. Rather, knockout studies suggested that $\beta 1$ integrins are primarily required for the integrity of the glia limitans [151]. Thus, their loss disrupts cellular layer formation through disruption of the radial scaffold; however, it does not directly affect neuronal migration, and it does not result in a reeler-like phenotype, suggesting that $\beta 1$ integrins are not essential for Reelin signaling in neurons [152]. Given the recent studies discussed above [117], the role of integrins in Reelin signaling cannot be completely dismissed. However, it seems likely that $\beta 1$-containing integrins in the cerebral cortex function in radial glial cells rather than in migrating neurons. This view is consistent with previous data demonstrating that Reelin and $\beta 1$ integrins are required for the formation of the radial glial scaffold in the hippocampus [153].

Another family of proteins that have been proposed to function as Reelin receptors is the Cadherin-related neuronal receptor (CNR) family, particularly CNR1 [154]. CNR proteins were found to be expressed in migrating neurons, bind the $\mathrm{N}$ terminal region of Reelin, and also associate with the SFK Fyn on the intracellular side. Their expression pattern and binding properties made them excellent candidates as Reelin receptors or coreceptors. However, the binding of CNR1 to Reelin was not replicated by other investigators [40].

In the past couple of years, new potential Reelin receptor systems have surfaced. Ephrin B proteins were reported to bind the $\mathrm{N}$ terminal region of Reelin and claimed to be essential components of the Reelin pathway in the control of neuronal migration [155]. However, as evident from the published corrigendum and the multitude of online comments related to this paper, many questions about 
the validity of the findings have been raised. Nevertheless, further investigations of these receptors have been conducted. Since ephrin B proteins bind to the EphB family of transmembrane receptor tyrosine kinases, which transduce bidirectional tyrosine kinase-mediated signals to both the Eph receptor-expressing (forward signaling) and the ephrinexpressing cell (reverse signaling), the potential role of these kinases in brain development and Reelin signaling was also investigated. One study found that ephrin-B1 interacting with EphB2 controls the migration of dentate progenitor cells into the dorsal half of the developing dentate gyrus, perhaps in part by affecting Reelin expression [156]. Recently, a new study showed that the $\mathrm{N}$ terminal region of Reelin binds to the extracellular domains of EphB transmembrane proteins, inducing receptor clustering and activation of EphB forward signaling in neurons, independently of ApoER2 and VLDLR [157]. However, mice lacking EphBs displayed a very mild migration phenotype that was limited to a modest positioning defect of CA3 hippocampal-pyramidal neurons. Thus, even though there appears to be some signal integration between Reelin and ephrin/EphB receptors, the physiological significance of this interaction for neuronal migration is rather limited. Based on a recent study, it appears that ephrin/Eph signaling may be more important for mediating contact repulsion among Cajal-Retzius cells to ensure the even distribution of these neurons in the brain [158].

Overall, the data available so far indicate that the activity of Reelin in the control of neuronal migration is predominantly mediated by ApoER2 and VLDLR receptors, whose functions are overlapping but not identical. Both receptors are involved in the activation of SFKs, Dabl phosphorylation on tyrosine residues, and the recruitment of Crk/CrkL, which lead to the activation of downstream events discussed above, which are essential for radial migration (Figure 2).

\section{Reelin-Regulated Growth of Cellular Processes}

In addition to controlling neuronal migration and layer formation in embryonic cortical structures, Reelin also plays an important role in promoting the growth and maturation of specific neuronal populations in the postnatal brain. As we mentioned above, the cellular source of Reelin in forebrain structures changes after birth. While Cajal-Retzius cells are the predominant population of Reelin-expressing cells in the marginal zone of the embryonic cerebral cortex and hippocampus, a subset of inhibitory, GABA-synthesizing neurons express Reelin and gradually become the predominant source of Reelin in the postnatal and adult forebrain [45, 68]. However, Cajal-Retzius cells are still present and remain the major source of Reelin during the first 1-2 weeks after birth in the early postnatal hippocampus. Transplantation studies demonstrated that this early postnatal source of Reelin is needed to promote the branching of axonal projections from the entorhinal-hippocampal pathway, which terminates in the marginal zone of the hippocampus and dentate gyrus (the outer molecular layer) $[20,58]$. However, since Reelin is a secreted protein, its functional range needs not to be limited to the growth of cellular processes that develop in the same layers that contain Reelin-expressing cells, that is, the marginal layers. Indeed, early studies had revealed extensive dendrite abnormalities throughout the hippocampus of homozygous reeler mice [60]. However, it was unclear from these anatomical observations whether dendrite defects were due primarily to cellular ectopia or were the direct result of Reelin deficiency. This issue was revised in recent years with a combination of novel in vivo and in vitro approaches. Taking advantage of a fluorescent transgene that was expressed in the postnatal forebrain, developing apical dendrites of dentate granule neurons were visualized in reeler mutant and control littermates. From this comparison, it was apparent that dendrite growth was delayed in reeler mice [62]. Furthermore, in vitro studies demonstrated that dendrite elongation and branching proceed at a reduced rate in immature hippocampal neurons obtained from reeler or Dab1 knockout mice and kept for 3-6 days in vitro (DIV), irrespective of neuronal positioning [62]. In this experimental assay, the addition of recombinant Reelin to the culture medium rescued the reeler defect in a manner that was dependent on the activity of lipoprotein receptors and Dab1. Thus, the same signaling pathway that controls neuronal migration before birth also mediated an early postnatal function of Reelin in the control of dendrite outgrowth, at least in immature hippocampal neurons. Following in vitro studies further revealed that the trophic effect of Reelin on dendrite outgrowth is dependent not only on Dabl and lipoprotein receptors, but also on other previously identified components of Reelin signaling, including Src kinases, Crks, PI3K, and Akt $[65,159]$. These studies also demonstrated that Reelin, acting through the well-known PI3K/Akt pathway, positively modulates the activity of the mTOR kinase, which is required for the stimulation of dendrite outgrowth, and activates downstream proteins, such as the p70S6K, that are known to participate in the control of protein translation. Few years later, other studies confirmed the activation of mTOR by Reelin and further demonstrated the increased phosphorylation of p70S6K and the downstream ribosomal protein S6, events that are completely dependent on SFK and PI3K activity [71]. To these days, however, the effects of Reelin on protein translation and its significance in terms of cell growth and dendrite morphogenesis have not been fully investigated.

In addition to the previously identified signaling cascade, the analysis of the molecular mechanisms of cellular and fiber layer formation led to the identification of potentially new players in Reelin signal transduction. A study revealed that serum response factor (SRF), a transcription factor that regulates synaptic-activity-induced immediateearly gene (IEG) induction and cytoskeleton-based neuronal motility, is important for hippocampal lamination and that this factor mediates the effect of Reelin on dendrite development [160]. This finding raised the intriguing possibility that Reelin might enhance F-actin stability by elevating IEG mRNA levels via SRF-dependent gene transcription. All the studies mentioned above utilized immature hippocampal cultures (3-6 DIV) and demonstrated a trophic effect of Reelin on the initial growth of dendrites. However, it should 


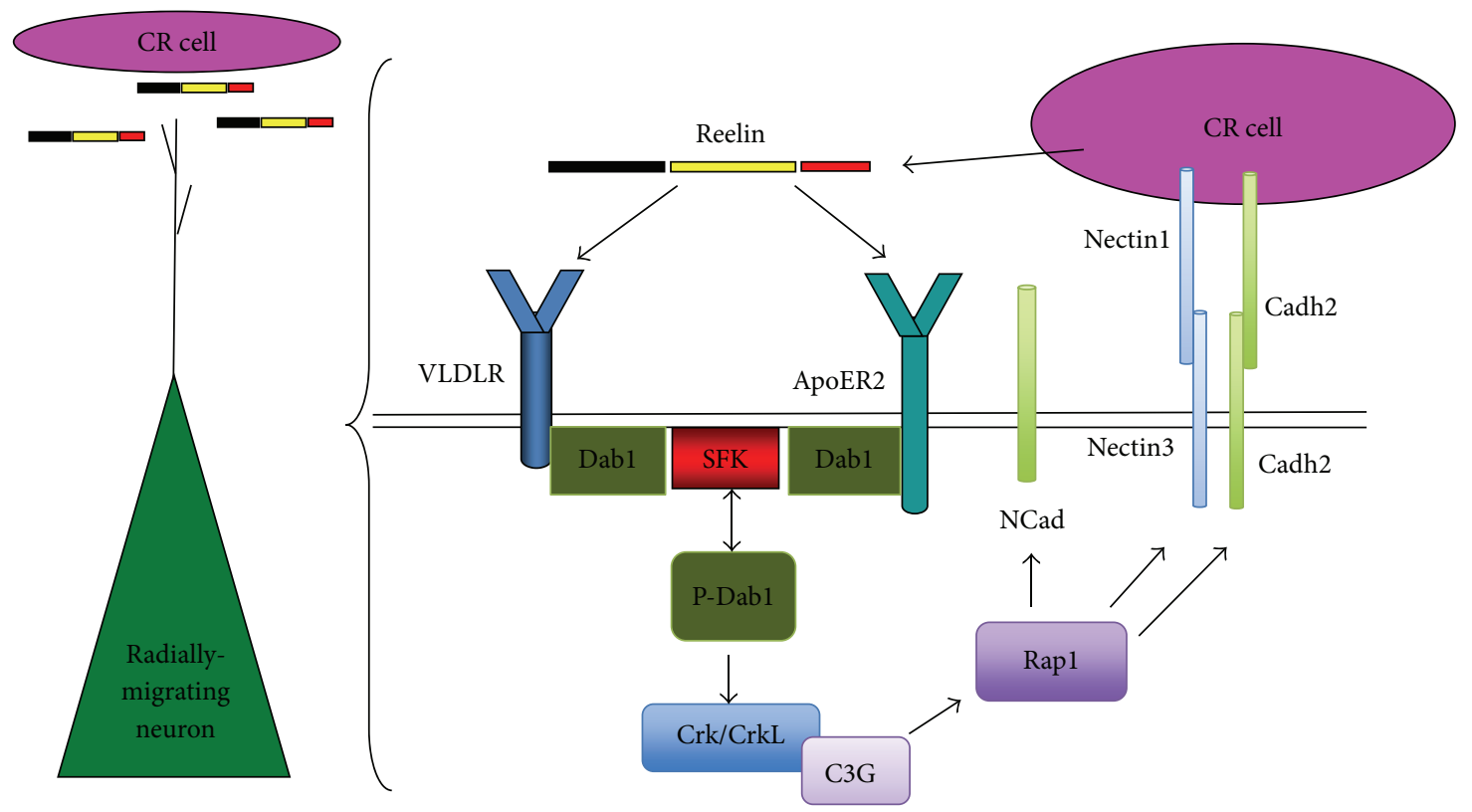

FIGURE 2: Diagram depicting the relationship between Reelin-secreting surface neurons and radially migrating neurons expressing the core signaling machinery (right). Surface neurons such as Cajal-Retzius cells (CR) secrete Reelin, which through its central region (yellow region) binds VLDLR and ApoER2 receptors on the surface of radially-migrating neurons. Ligand binding causes the activation of SFKs Src and Fyn, and the phosphorylation of the Dabl adaptor protein. This event results in the recruitment of Crk/CrkL adaptor proteins mediate further downstream signaling through C3G and Rap1, resulting in the surface expression of N-Cadherin (Ncad), which is required for radial orientation, and activation of Nectinl-Nectin3, and homophilic Cadherin 2 (Cadh2) cell-cell interactions that are required to complete radial migration by somal translocation.

be noted that in vitro studies utilizing mature hippocampal cultures (18-20 DIV) obtained from Dabl knockout mice demonstrated that, although Reelin-Dab1 signaling promotes initial hippocampal dendrite development, it is not required for neurons to reach full maturity [67]. Thus, as for entorhinohippocampal axons, hippocampal dendrite outgrowth is stimulated by Reelin during early neuronal development, but neurons do not require Reelin signaling to reach their full morphological maturity, as other growth factors likely compensate and promote the growth of these processes even in the absence of Reelin signaling.

What cellular mechanisms underlie the control of neurite development by Reelin? Recent studies showed that the Golgi apparatus is abnormal in reeler and Dab1 knockout mice and that Reelin treatment rapidly induced the deployment of the Golgi apparatus into dendrites of cultured neurons [66]. Mechanistically, it was demonstrated that Reelin-Dab1 signaling antagonizes the effects of Stk25, a scaffolding protein that links the LKB1-STRAD-GM130 complex to neuronal polarization. Other studies have shown that Reelin increases growth cone motility and filopodia formation, through activation of the Rho GTPase Cdc42, in an ApoER2-, Dab1-, and PI3K-dependent manner [161]. Building on these findings, a recent study further demonstrated that the $\mathrm{Cdc} 42 / \mathrm{Racl}$ guanine nucleotide exchange factor $\alpha$ PIX/Arhgef6 promoted translocation of Golgi cisternae into developing dendrites of hippocampal neurons [162]. Reelin increased the $\alpha$ PIXdependent effect and promoted the translocation of the Golgi apparatus into the dendrite that was most proximal to the Reelin source. These observations led to the interesting conclusion that the spatial distribution of Reelin may contribute to the selection of the neuritic process that becomes the apical dendrite.

In addition to in vitro studies, in vivo studies demonstrated that the effect of Reelin on dendrite development is closely coupled to neuronal migration and is an important aspect of cellular layer formation. An examination of the morphology of Dabl knockdown neurons in the late embryonic and early postnatal neocortex revealed simplified leading processes that were less likely to contact the Reelin-rich marginal zone [64]. These data confirmed a cell-autonomous role of Dab1 in dendritogenesis in the neocortex and suggested that remodeling of the leading process of a migrating neuron into a nascent dendrite by Reelin/Dabl signaling plays an important role in final cell positioning. Furthermore, it was shown that Reelin injection in vivo caused deep cortical neurons to reorient their nuclei and polarize their Golgi toward the pia while initiating exuberant dendritic outgrowth within few hours [63]. Thus, Reelin exerts a direct role in promoting the rapid morphological differentiation and orientation of deep cortical neurons during early corticogenesis.

Finally, other in vivo studies indicated that Reelin not only promotes growth but also promotes the selective pruning of dendritic process in cortical neurons [163]. This study implicated serotonin 5-HT(3) receptor and Reelin signaling in the control of the complexity of apical dendrites of cortical layer II/III pyramidal neurons. Relevant to Reelin activity, these authors found that injection of Reelin antibodies resulted in increased dendritic complexity, whereas the application of recombinant full-length Reelin rescued 
this defect. Surprisingly, however, they found that pruning was also achieved when the N-terminal fragment, but not the central fragment of Reelin, was injected. This study also suggested that the $\mathrm{N}$ terminal region of Reelin mediates dendrite refinement through receptors other than ApoER2 and VLDLR, consistent with previous observations that only the central fragment of Reelin can bind and engage these receptors [40]. The mechanisms of the Reelin-mediated regulation of dendrite growth may thus be more complex than initially envisioned, and it may vary depending on the cell type examined. For example, other investigators found that the amyloid precursor protein (APP) promotes the growth of cortical dendrites in vivo and is required for Reelininduced dendrite growth in cultured hippocampal neurons [164]. This finding builds on previous reports that APP family members interact with Dabl due to their NPxY motif [85, 86] and that Reelin signaling affects APP processing [165]. Mechanistically, the new study found that APP interacts with the central fragment of Reelin and with $\alpha 3 \beta 1$ integrin. Since an $\alpha 3 \beta 1$ antibody prevented APP and Reelin-induced neurite outgrowth, this study implicated integrins in Reelin signaling controlling neurite development.

\section{Reelin Functions in Synaptogenesis and Spine Formation}

As postnatal development continues and Cajal-Retzius cells progressively disappear from the forebrain, the expression of Reelin becomes predominantly localized to interneurons. A subset of GABAergic interneurons express Reelin throughout all cellular layers of the rodent neocortex and hippocampus at postnatal and adult ages $[45,68]$. Since its early discovery, the physiological role of this new pattern of expression has been the subject of intense inquiry, given that the function of Reelin in the late postnatal and adult forebrain could no longer be related to neuronal migration or dendrite development in these brain regions. Attention turned to synapse development and function, since these biological processes predominate at later postnatal ages. The first documented evidence that Reelin plays a role in synapse formation in the forebrain related to the development of entorhinohippocampal connections [58]. Since Reelin had previously been implicated in the branching of this axonal projection, the finding appeared to be a logical extension of previous observations: the more axonal terminals are formed, the more they can synapse on hippocampal target cells. Therefore, the effect on synapse development initially appeared indirect and secondary to that on axonal branching. Nevertheless, adding support to a role for Reelin signaling in synaptogenesis, few years later came the observation that Reelin and Dabl modulate the structure and function of retinal synaptic circuitry [19]. This paper showed that, even though there is no cellular ectopia in the highly laminated structure of the retina in reeler or Dab1 mutant mice, connectivity defects are present which ultimately lead to altered physiological responses. Thus, this paper was significant because it highlighted a role for the Reelin pathway in the formation and functional output of a specific synaptic circuitry, independent of cell position. In the retina, Reelin is expressed not only by retinal ganglion cells, but also by some amacrine and cone bipolar cells, whereas Dab1 is expressed almost exclusively by AII amacrine cells [19]. These Dabl-positive cells play an essential role in mediating Reelin signaling and establishing retinal synaptic circuitry. A recent study revealed that, as in other parts of the central nervous system, ApoER2 and VLDLR function as Reelin receptors and are both required for the establishment and maintenance of normal retinal synaptic connectivity [166]. However, they appear to contribute differently to the development and maintenance of retinal synaptic connectivity. ApoER2 is predominantly expressed by both AII amacrine cells and other amacrine or bipolar cells in the developing retina and plays a role in the development of the rod bipolar pathway, whereas VLDLR is required for the establishment of oscillatory potentials [166].

In the forebrain, studies of heterozygous reeler mice emphasized a direct role for Reelin in the control of synaptogenesis, particularly in the formation of the excitatory postsynaptic structures. Heterozygous reeler mice express half the Reln mRNA levels of wild type mice and appear phenotypically normal in that they do not exhibit ataxia or layer defects in any brain region [1]. However, these mice exhibit behavioral and cognitive defects reminiscent of those found in human psychoses [167, 168] and are thus considered animal models for the disease [169]. The behavioral phenotype of heterozygous reeler mice has been challenged by other investigators [170] however, these mice do appear to have subtle anatomical abnormalities that would account for functional connectivity problems. For example, they exhibit delayed growth of dendritic processes in hippocampal neurons [62] and a reduction in the density of synaptic contacts in the frontal [171] and prefrontal cortex [127]. Defects in dendritic spine density were also found in the hippocampus of heterozygous reeler and Dab1 knockout mice, accompanied by altered molecular composition of the synaptosomes [70]. This study also showed that Reelin treatment rescued spine density defects of reeler organotypic hippocampal slices in a manner that was dependent on all core components of the signaling pathway, namely, the lipoprotein receptors ApoER2 and VLDLR, SFKs and Dab1 [70]. Follow-up studies revealed that defects in spine density are transient in heterozygous reeler mice and essentially disappear in adult mice by 2 months of age; however, the expression of postsynaptic proteins, including NMDA receptor subunits, remains altered [71]. In a complementary study, other investigators examined spine density and size in transgenic mice that overexpressed Reelin and found that Reelin overexpression caused an increase in spine size but did not change spine density in hippocampal regions [75]. Consistent with this view, a recent study in which a single dose of Reelin was injected in the hippocampus of live adult mice indicated that acute administration of Reelin alters dendritic spine morphology but not spine density [172]. In contrast, long-term administration (5 days) of Reelin in vivo also increases spine density [173]. Taken together, these studies suggest that subthreshold levels of Reelin are deleterious because they delay the normal development of excitatory synapses, but a chronic excess of Reelin may 
also be disruptive because it alters spine morphology and number. Finally, it should be noted that reduced spontaneous inhibitory postsynaptic potentials have been reported in adult reeler heterozygous mice [167], suggesting that Reelin may play a significant role in the development of inhibitory synapses. However, this topic has not been yet investigated at a cellular and molecular level.

\section{Adult Function of Reelin in the Modulation of Synaptic Activity}

Reelin-expressing interneurons in the adult forebrain were identified as a heterogeneous population of bitufted, horizontal, and multipolar cells coexpressing either calretinin, calbindin, somatostatin, or NPY but not parvalbumin [45, 68]. A similar pattern of Reelin expression in selected interneurons was also observed in primates at postnatal ages [174]. In humans, the selective expression of Reelin in interneurons, together with the observed decrease in the expression of Reelin [25] and other interneuron markers in the postmortem brains of schizophrenic patients, led to the hypothesis that Reelin deficiency contributes to interneuron dysfunction in this disorder [30]. Reelin deficiency is recapitulated in the heterozygous reeler mouse, which exhibited subtle neuroanatomical abnormalities, such as decreased neuropil and dendritic spine density $[70,171]$, reminiscent of the changes reported in the brain of schizophrenia patients [175]. Heterozygous reeler mice also exhibit altered hippocampal synaptic function [167] and multiple behavioral abnormalities that parallel those noted in schizophrenia, such as defects in executive function [170, 176], contextual fear conditioning learning, and crossmodal prepulse inhibition $[167,177]$. Thus, these mutant mice are useful models for understanding the cellular basis of behavioral and cognitive defects characterizing schizophrenia [169].

What is the significance of normal adult Reelin expression? Histochemical and ultrastructural studies revealed that extracellular Reelin accumulates around synapses [174, 178180], leading to the suggestion that it may play a role in synaptic function. Indeed, a large body of evidence now suggests that this is the main function of Reelin in the adult brain. The first direct evidence that Reelin regulates synaptic function came from physiological studies using hippocampal slice cultures. In this acute in vitro system, Reelin treatment was shown to promote robust long-term potentiation (LTP) [181]. This study also showed that Reelin promotes hippocampal LTP in a manner that is dependent on both VLDLR and ApoER2. However, a following study further revealed that a particular splicing variant of ApoER2 capable of interacting with the NMDA receptor through PSD95 was required for Reelin-induced LTP $[149,181]$. A number of electrophysiological studies using dissociated neuronal cultures demonstrated that Reelin increases synaptic activity by affecting postsynaptic NMDA and AMPA receptor activity [182-186] and also promotes neurotransmitter release [187]. Long-term Reelin treatment was found to alter the subunit composition of the NMDA receptor, favoring maturation of this receptor, and to increase AMPA receptor insertion in the plasma membrane, thus reducing the number of silent synapses. Other studies further demonstrated that the LTP enhancement by brief Reelin stimulation is associated with increased $\mathrm{Ca}^{++}$influx through the NMDA receptor $[149,183,186]$. Using an in vivo approach, the effect of chronic exposure was examined in transgenic mice that overexpressed Reelin under the control of the adult-forebrain specific CamKII $\alpha$ promoter [75]. Reelin overexpressing mice displayed a dramatic dendritic spine hypertrophy but no changes in synaptic density, suggesting a specific function in the control of the size of excitatory synapses, which is highly related to their level of activity. Physiological recordings from hippocampal slices further documented an increase in LTP responses as well as neuronal activity during classical conditioning [75]. Using a different in vivo approach, other investigators injected Reelin directly into the hippocampus of adult mice and documented increases in synaptic plasticity, which correlated with enhanced cognitive performance in hippocampal-dependent tasks [173]. The role of Dabl signaling in adult synaptic plasticity and learning was very recently addressed in a study that also utilized the adult-forebrain specific CamKII $\alpha$ promoter, this time to drive conditional Dab1 gene deletion [128]. This study demonstrated the critical role of Dab1, not only in mediating hippocampal LTP and especially the enhancing effect of Reelin on LTP, but also in modulating basal and plasticity-induced Erk signaling, and promoting hippocampal-dependent associative learning and the consolidation of long-term spatial memory.

Taken together, these findings indicate that Reelin-Dab1 signaling plays an important role in modulating synaptic function in the adult forebrain and significantly affects memory formation and cognitive function. The observed effects of Reelin signaling on synaptic development and function suggest that this pathway is potentially an excellent target for intervention in the treatment of cognitive diseases associated with Reelin deficiency, such as schizophrenia, autism, epilepsy, or Alzheimer's disease. The involvement of Reelin in neurodevelopmental or neurodegenerative disease and the potential implications for treatment have been recently reviewed and discussed in detail [28, 188]. However, further studies are needed to fully understand the impact of the Reelin signaling pathway on brain development and function in order to develop effective and safe therapeutic agents.

\section{Conflict of Interests}

The author declares that there is no conflict of interests regarding the publication of this paper.

\section{References}

[1] G. D’Arcangelo, G. G. Miao, S.-C. Chen, H. D. Soares, J. I. Morgan, and T. Curran, "A protein related to extracellular matrix proteins deleted in the mouse mutant reeler," Nature, vol. 374, no. 6524, pp. 719-723, 1995.

[2] J. B. Angevine Jr. and R. L. Sidman, "Autoradiographic study of cell migration during histogenesis of cerebral cortex in the mouse," Nature, vol. 192, no. 4804, pp. 766-768, 1961. 
[3] V. S. Caviness Jr. and P. Rakic, "Mechanisms of cortical development: a view from mutations in mice," Annual Review of Neuroscience, vol. 1, pp. 297-326, 1978.

[4] D. S. Falconer, "Two new mutants, "trembler" and "reeler", with neurological actions in the house mouse (Mus musculus L.)," Journal of Genetics, vol. 50, no. 2, pp. 192-205, 1951.

[5] A. M. Goffinet, "Events governing organization of postmigratory neurons: studies on brain development in normal and reeler mice," Brain Research, vol. 319, no. 3, pp. 261-296, 1984.

[6] C. Lambert de Rouvroit and A. M. Goffinet, "The reeler mouse as a model of brain development," Advances in Anatomy, Embryology, and Cell Biology, vol. 150, pp. 1-106, 1998.

[7] J. Mariani, F. Crepel, K. Mikoshiba, J. P. Changeux, and C. Sotelo, "Anatomical, physiological and biochemical studies of the cerebellum from Reeler mutant mouse," Philosophical Transactions of the Royal Society of London. Series B, vol. 281, no. 978, pp. 1-28, 1977.

[8] K. Mikoshiba, S. Kohsaka, and K. Takamatsu, "Morphological and biochemical studies on the cerebral cortex from reeler mutant mice: development of cortical layers and metabolic mapping by the deoxyglucose method," Journal of Neurochemistry, vol. 34, no. 4, pp. 835-844, 1980.

[9] M. C. Pinto Lord, P. Evrard, and V. S. Caviness Jr., "Obstructed neuronal migration along radial glial fibers in the neocortex of the Reeler mouse: a Golgi-EM analysis," Developmental Brain Research, vol. 4, no. 4, pp. 379-393, 1982.

[10] P. Rakic and V. S. Caviness Jr., "Cortical development: view from neurological mutants two decades later," Neuron, vol. 14, no. 6, pp. 1101-1104, 1995.

[11] S. Hirotsune, T. Takahara, N. Sasaki et al., "The reeler gene encodes a protein with an EGF-like motif expressed by pioneer neurons," Nature Genetics, vol. 10, no. 1, pp. 77-83, 1995.

[12] S. Kikkawa, T. Yamamoto, K. Misaki et al., "Missplicing resulting from a short deletion in the reelin gene causes reeler-like neuronal disorders in the mutant shaking rat Kawasaki," Journal of Comparative Neurology, vol. 463, no. 3, pp. 303-315, 2003.

[13] N. Yokoi, M. Namae, H.-Y. Wang et al., "Rat neurological disease creeping is caused by a mutation in the reelin gene," Molecular Brain Research, vol. 112, no. 1-2, pp. 1-7, 2003.

[14] U. DeSilva, G. D’Arcangelo, V. V. Braden et al., "The human reelin gene: isolation, sequencing, and mapping on chromosome 7," Genome Research, vol. 7, no. 2, pp. 157-164, 1997.

[15] S. E. Hong, Y. Y. Shugart, D. T. Huang et al., "Autosomal recessive lissencephaly with cerebellar hypoplasia is associated with human RELN mutations," Nature Genetics, vol. 26, no. 1, pp. 93-96, 2000.

[16] P. E. Phelps, R. Rich, S. Dupuy-Davies, Y. Ríos, and T. Wong, "Evidence for a cell-specific action of Reelin in the spinal cord," Developmental Biology, vol. 244, no. 1, pp. 180-198, 2002.

[17] M. D. Kubasak, R. Brooks, S. Chen, S. A. Villeda, and P. E. Phelps, "Developmental distribution of reelin-positive cells and their secreted product in the rodent spinal cord," Journal of Comparative Neurology, vol. 468, no. 2, pp. 165-178, 2004.

[18] J. W. Yip, Y. P. L. Yip, K. Nakajima, and C. Capriotti, "Reelin controls position of autonomic neurons in the spinal cord," Proceedings of the National Academy of Sciences of the United States of America, vol. 97, no. 15, pp. 8612-8616, 2000.

[19] D. S. Rice, S. Nusinowitz, A. M. Azimi, A. Martínez, E. Soriano, and T. Curran, "The Reelin pathway modulates the structure and fof retinal synaptic circuitry," Neuron, vol. 31, no. 6, pp. 929941, 2001.
[20] J. A. Del Río, B. Heimrich, V. Borrell et al., "A role for Cajalretzius cells and reelin in the development of hippocampal connections," Nature, vol. 385, no. 6611, pp. 70-74, 1997.

[21] T. Deller, A. Drakew, B. Heimrich, E. Förster, A. Tielsch, and M. Frotscher, "The hippocampus of the reeler mutant mouse: fiber segregation in area CAl depends on the position of the postsynaptic target cells," Experimental Neurology, vol. 156, no. 2, pp. 254-267, 1999.

[22] I. Royaux, C. L. De Rouvroit, G. D’Arcangelo, D. Demirov, and A. M. Goffinet, "Genomic organization of the mouse reelin gene," Genomics, vol. 46, no. 2, pp. 240-250, 1997.

[23] Y. Chen, R. P. Sharma, R. H. Costa, E. Costa, and D. R. Grayson, "On the epigenetic regulation of the human reelin promoter," Nucleic Acids Research, vol. 30, no. 13, pp. 2930-2939, 2002.

[24] C. P. Mitchell, Y. Chen, M. Kundakovic, E. Costa, and D. R. Grayson, "Histone deacetylase inhibitors decrease reelin promoter methylation in vitro," Journal of Neurochemistry, vol. 93, no. 2, pp. 483-492, 2005.

[25] F. Impagnatiello, A. R. Guidotti, C. Pesold et al., "A decrease of reelin expression as a putative vulnerability factor in schizophrenia," Proceedings of the National Academy of Sciences of the United States of America, vol. 95, no. 26, pp. 15718-15723, 1998.

[26] A. Guidotti, J. Auta, J. M. Davis et al., "Decrease in reelin and glutamic acid decarboxylase67 (GAD67) expression in schizophrenia and bipolar disorder: a postmortem brain study," Archives of General Psychiatry, vol. 57, no. 11, pp. 1061-1069, 2000.

[27] S. H. Fatemi, "The role of Reelin in pathology of autism," Molecular Psychiatry, vol. 7, no. 9, pp. 919-920, 2002.

[28] T. D. Folsom and S. H. Fatemi, "The involvement of Reelin in neurodevelopmental disorders," Neuropharmacology, vol. 68, pp. 122-135, 2012.

[29] D. R. Grayson, Y. Chen, E. Costa et al., “The human reelin gene: transcription factors $(+)$, repressors $(-)$ and the methylation switch (+/-) in schizophrenia," Pharmacology and Therapeutics, vol. 111, no. 1, pp. 272-286, 2006.

[30] A. Guidotti, J. Auta, J. M. Davis et al., "GABAergic dysfunction in schizophrenia: new treatment strategies on the horizon," Psychopharmacology, vol. 180, no. 2, pp. 191-205, 2005.

[31] G. D’Arcangelo, K. Nakajima, T. Miyata, M. Ogawa, K. Mikoshiba, and T. Curran, "Reelin is a secreted glycoprotein recognized by the CR-50 monoclonal antibody," Journal of Neuroscience, vol. 17, no. 1, pp. 23-31, 1997.

[32] M. Ogawa, T. Miyata, K. Nakajima et al., "The realer geneassociated antigen on cajal-retzius neurons is a crucial molecule for laminar organization of cortical neurons," Neuron, vol. 14, no. 5, pp. 899-912, 1995.

[33] G. D’Arcangelo, R. Homayouni, L. Keshvara, D. S. Rice, M. Sheldon, and T. Curran, "Reelin is a ligand for lipoprotein receptors," Neuron, vol. 24, no. 2, pp. 471-479, 1999.

[34] T. Miyata, K. Nakajima, K. Mikoshiba, and M. Ogawa, "Regulation of Purkinje cell alignment by Reelin as revealed with CR-50 antibody," Journal of Neuroscience, vol. 17, no. 10, pp. 3599-3609, 1997.

[35] M. Sinagra, D. Verrier, D. Frankova et al., "Reelin, very-lowdensity lipoprotein receptor, and apolipoprotein $\mathrm{E}$ receptor 2 control somatic NMDA receptor composition during hippocampal maturation in vitro," Journal of Neuroscience, vol. 25, no. 26, pp. 6127-6136, 2005. 
[36] K.-I. Kubo, K. Mikoshiba, and K. Nakajima, "Secreted Reelin molecules form homodimers," Neuroscience Research, vol. 43, no. 4, pp. 381-388, 2002.

[37] N. Yasui, T. Nogi, T. Kitao, Y. Nakano, M. Hattori, and J. Takagi, "Structure of a receptor-binding fragment of reelin and mutational analysis reveal a recognition mechanism similar to endocytic receptors," Proceedings of the National Academy of Sciences of the United States of America, vol. 104, no. 24, pp. 9988-9993, 2007.

[38] Y. Nakano, T. Kohno, T. Hibi et al., "The extremely conserved C-terminal region of Reelin is not necessary for secretion but is required for efficient activation of downstream signaling," Journal of Biological Chemistry, vol. 282, no. 28, pp. 2054420552, 2007.

[39] V. de Bergeyck, B. Naerhuyzen, A. M. Goffinet, and C. Lambert de Rouvroit, "A panel of monoclonal antibodies against reelin, the extracellular matrix protein defective in reeler mutant mice," Journal of Neuroscience Methods, vol. 82, no. 1, pp. 17-24, 1998.

[40] Y. Jossin, N. Ignatova, T. Hiesberger, J. Herz, C. Lambert De Rouvroit, and A. M. Goffinet, "The central fragment of Reelin, generated by proteolytic processing in vivo, is critical to its function during cortical plate development," Journal of Neuroscience, vol. 24, no. 2, pp. 514-521, 2004.

[41] Y. Jossin, L. Gui, and A. M. Goffinet, "Processing of Reelin by embryonic neurons is important for function in tissue but not in dissociated cultured neurons," Journal of Neuroscience, vol. 27, no. 16, pp. 4243-4252, 2007.

[42] N. Utsunomiya-Tate, K.-I. Kubo, S.-I. Tate et al., "Reelin molecules assemble together to form a large protein complex, which is inhibited by the function-blocking CR-50 antibody," Proceedings of the National Academy of Sciences of the United States of America, vol. 97, no. 17, pp. 9729-9734, 2000.

[43] Y. Ikeda and T. Terashima, "Expression of reelin, the gene responsible for the Reeler mutation, in embryonic development and adulthood in the mouse," Developmental Dynamics, vol. 210, pp. 157-172, 1997.

[44] S. N. Schiffmann, "Reelin mRNA expression during mouse brain development," European Journal of Neuroscience, vol. 9, no. 5, pp. 1055-1071, 1997.

[45] S. Alcántara, M. Ruiz, G. D’Arcangelo et al., "Regional and cellular patterns of reelin mRNA expression in the forebrain of the developing and adult mouse," Journal of Neuroscience, vol. 18, no. 19, pp. 7779-7799, 1998.

[46] T. Miyata, K. Nakajima, J. Aruga et al., "Distribution of the reeler gene-related antigen in the developing cerebellum: an immunohistochemical study with an allogenic antibody CR-50 on normal and reeler mice," Journal of Comparative Neurology, vol. 372, pp. 215-228, 1996.

[47] A. Drakew, M. Frotscher, T. Deller, M. Ogawa, and B. Heimrich, "Developmental distribution of a reeler gene-related antigen in the rat hippocampal formation visualized by CR-50 immunocytochemistry," Neuroscience, vol. 82, no. 4, pp. 1079-1086, 1997.

[48] G. Meyer, J. M. Soria, J. R. Martinez-Galan, B. Martin-Clemente, and A. Fairen, "Different origins and developmental histories of transient neurons in the marginal zone of the fetal and neonatal rat cortex," Journal of Comparative Neurology, vol. 397, pp. 493518, 1998.

[49] G. Meyer and A. M. Goffinet, "Prenatal development of Reelinimmunoreactive neurons in the human neocortex," Journal of Comparative Neurology, vol. 397, pp. 29-40, 1998.
[50] E. Förster, S. Zhao, and M. Frotscher, "Laminating the hippocampus," Nature Reviews Neuroscience, vol. 7, no. 4, pp. 259267, 2006.

[51] V. Duveau, A. Madhusudan, M. Caleo, I. Knuesel, and J.-M. Fritschy, "Impaired reelin processing and secretion by CajalRetzius cells contributes to granule cell dispersion in a mouse model of temporal lobe epilepsy," Hippocampus, vol. 21, no. 9, pp. 935-944, 2011.

[52] C. A. Haas, O. Dudeck, M. Kirsch et al., "Role for reelin in the development of granule cell dispersion in temporal lobe epilepsy," Journal of Neuroscience, vol. 22, no. 14, pp. 5797-5802, 2002.

[53] C. Heinrich, N. Nitta, A. Flubacher et al., "Reelin deficiency and displacement of mature neurons, but not neurogenesis, underlie the formation of granule cell dispersion in the epileptic hippocampus," Journal of Neuroscience, vol. 26, no. 17, pp. 47014713, 2006.

[54] A. M. Goffinet, "The embryonic development of the cerebellum in normal and reeler mutant mice," Anatomy and Embryology, vol. 168, no. 1, pp. 73-86, 1983.

[55] Y. Inoue, N. Maeda, T. Kokubun et al., "Architecture of Purkinje cells of the reeler mutant mouse observed by immunohistochemistry for the inositol 1,4,5-trisphoshate receptor protein P400," Neuroscience Research, vol. 8, no. 3, pp. 189-201, 1990.

[56] K. Mikoshiba, K. Nagaike, and S. Kohsaka, "Developmental studies on the cerebellum from reeler mutant mouse in vivo and in vitro," Developmental Biology, vol. 79, no. 1, pp. 64-80, 1980.

[57] M. Frotscher, "Dual role of Cajal-Retzius cells and reelin in cortisal development," Cell and Tissue Research, vol. 290, no. 2, pp. 315-322, 1997.

[58] V. Borrell, J. A. Del Río, S. Alcántara et al., "Reelin regulates the development and synaptogenesis of the layer-specific entorhino-hippocampal connections," Journal of Neuroscience, vol. 19, no. 4, pp. 1345-1358, 1999.

[59] M. C. Pinto Lord and V. S. Caviness Jr., "Determinants of cell shape and orientation: a comparative Golgi analysis of cell-axon interrelationships in the developing neocortex of normal and reeler mice," Journal of Comparative Neurology, vol. 187, no. 1, pp. $49-70,1979$.

[60] B. B. Stanfield and W. M. Cowan, "The development of the hippocampus and dentate gyrus in normal and reeler mice," Journal of Comparative Neurology, vol. 185, no. 3, pp. 423-459, 1979.

[61] B. B. Stanfield and W. M. Cowan, "The morphology of the hippocampus and dentate gyrus in normal and reeler mice," Journal of Comparative Neurology, vol. 185, no. 3, pp. 393-422, 1979.

[62] S. Niu, A. Renfro, C. C. Quattrocchi, M. Sheldon, and G. D’Arcangelo, "Reelin promotes hippocampal dendrite development through the VLDLR/ApoER2-Dab1 pathway," Neuron, vol. 41, no. 1, pp. 71-84, 2004.

[63] A. J. Nichols and E. C. Olson, "Reelin promotes neuronal orientation and dendritogenesis during preplate splitting," Cerebral Cortex, vol. 20, no. 9, pp. 2213-2223, 2010.

[64] E. C. Olson, S. Kim, and C. A. Walsh, "Impaired neuronal positioning and dendritogenesis in the neocortex after cellautonomous Dabl suppression," Journal of Neuroscience, vol. 26, no. 6, pp. 1767-1775, 2006.

[65] Y. Jossin and A. M. Goffinet, "Reelin signals through phosphatidylinositol 3-kinase and Akt to control cortical development and through mTor to regulate dendritic growth," Molecular and Cellular Biology, vol. 27, no. 20, pp. 7113-7124, 2007. 
[66] T. Matsuki, R. T. Matthews, J. A. Cooper et al., "Reelin and Stk25 have opposing roles in neuronal polarization and dendritic Golgi deployment," Cell, vol. 143, no. 5, pp. 826-836, 2010.

[67] S. A. MacLaurin, T. Krucker, and K. N. Fish, "Hippocampal dendritic arbor growth in vitro: regulation by Reelin-disabled-1 signaling," Brain Research, vol. 1172, no. 1, pp. 1-9, 2007.

[68] C. Pesold, F. Impagnatiello, M. G. Pisu et al., "Reelin is preferentially expressed in neurons synthesizing $\gamma$-aminobutyric acid in cortex and hippocampus of adult rats," Proceedings of the National Academy of Sciences of the United States of America, vol. 95, no. 6, pp. 3221-3226, 1998.

[69] O. Yabut, A. Renfro, S. Niu, J. W. Swann, O. Marín, and G. D'Arcangelo, "Abnormal laminar position and dendrite development of interneurons in the reeler forebrain," Brain Research, vol. 1140, no. 1, pp. 75-83, 2007.

[70] S. Niu, O. Yabut, and G. D’Arcangelo, “The reelin signaling pathway promotes dendritic spine development in hippocampal neurons," Journal of Neuroscience, vol. 28, no. 41, pp. 1033910348, 2008.

[71] A. Ventruti, T. M. Kazdoba, S. Niu, and G. D’Arcangelo, “Reelin deficiency causes specific defects in the molecular composition of the synapses in the adult brain," Neuroscience, vol. 189, pp. 32-42, 2011.

[72] V. S. Caviness Jr. and R. L. Sidman, "Time of origin or corresponding cell classes in the cerebral cortex of normal and reeler mutant mice: an autoradiographic analysis," Journal of Comparative Neurology, vol. 148, no. 2, pp. 141-151, 1973.

[73] V. S. Caviness Jr., "Time of neuron origin in the hippocampus and dentate gyrus of normal and reeler mutant mice: an autoradiographic analysis," Journal of Comparative Neurology, vol. 151, no. 2, pp. 113-120, 1973.

[74] A. M. Goffinet, "An early developmental defect in the cerebral cortex of the reeler mouse. A morphological study leading to a hypothesis concerning the action of the mutant gene," Anatomy and Embryology, vol. 157, no. 2, pp. 205-216, 1979.

[75] L. Pujadas, A. Gruart, C. Bosch et al., "Reelin regulates postnatal neurogenesis and enhances spine hypertrophy and long-term potentiation," Journal of Neuroscience, vol. 30, no. 13, pp. 46364649, 2010.

[76] T. Terashima, K. Inoue, and Y. Inoue, "Observations on the cerebellum of normal-reeler mutant mouse chimera," Journal of Comparative Neurology, vol. 252, no. 2, pp. 264-278, 1986.

[77] K. H. Weiss, C. Johanssen, A. Tielsch et al., "Malformation of the radial glial scaffold in the dentate gyrus of reeler mice, scrambler mice, and ApoER2/VLDLR-deficient mice," Journal of Comparative Neurology, vol. 460, no. 1, pp. 56-65, 2003.

[78] K. E. Hunter-Schaedle, "Radial glial cell development and transformation are disturbed in reeler forebrain," Journal of Neurobiology, vol. 33, pp. 459-472, 1997.

[79] P. Malatesta, E. Hartfuss, and M. Götz, "Isolation of radial glial cells by fluorescent-activated cell sorting reveals a neural lineage," Development, vol. 127, no. 24, pp. 5253-5263, 2000.

[80] S. C. Noctor, A. C. Flint, T. A. Weissman, R. S. Dammerman, and A. R. Kriegstein, "Neurons derived from radial glial cells establish radial units in neocortex," Nature, vol. 409, no. 6821, pp. 714-720, 2001.

[81] B. Nadarajah, J. E. Brunstrom, J. Grutzendler, R. O. L. Wong, and A. L. Pearlman, "Two modes of radial migration in early development of the cerebral cortex," Nature Neuroscience, vol. 4, no. 2, pp. 143-150, 2001.
[82] H. Tabata and K. Nakajima, "Multipolar migration: the third mode of radial neuronal migration in the developing cerebral cortex," Journal of Neuroscience, vol. 23, no. 31, pp. 9996-10001, 2003.

[83] I. Hack, M. Bancila, K. Loulier, P. Carroll, and H. Cremer, "Reelin is a detachment signal in tangential chain-migration during postnatal neurogenesis," Nature Neuroscience, vol. 5, no. 10, pp. 939-945, 2002.

[84] B. W. Howell, F. B. Gertler, and J. A. Cooper, "Mouse disabled (mDab1): a Src binding protein implicated in neuronal development," The MBO Journal, vol. 16, no. 1, pp. 121-132, 1997.

[85] R. Homayouni, D. S. Rice, M. Sheldon, and T. Curran, "Disabled-1 binds to the cytoplasmic domain of amyloid precursor-like protein 1," Journal of Neuroscience, vol. 19, no. 17, pp. 7507-7515, 1999.

[86] B. W. Howell, L. M. Lanier, R. Frank, F. B. Gertler, and J. A. Cooper, "The disabled 1 phosphotyrosine-binding domain binds to the internalization signals of transmembrane glycoproteins and to phospholipids," Molecular and Cellular Biology, vol. 19, no. 7, pp. 5179-5188, 1999.

[87] P. C. Stolt, H. Jeon, H. K. Song, J. Herz, M. J. Eck, and S. C. Blacklow, "Origins of peptide selectivity and phosphoinositide binding revealed by structures of disabled-1 PTB domain complexes," Structure, vol. 11, no. 5, pp. 569-579, 2003.

[88] D. Goldowitz, R. C. Gushing, E. Laywell et al., "Cerebellar disorganization characteristic of reeler in scrambler mutant mice despite presence of reelin," Journal of Neuroscience, vol. 17, no. 22, pp. 8767-8777, 1997.

[89] M. Sheldon, D. S. Rice, G. D’Arcangelo et al., "Scrambler and yotari disrupt the disabled gene and produce a reeler-like phenotype in mice," Nature, vol. 389, no. 6652, pp. 730-733, 1997.

[90] M. L. Ware, J. W. Fox, J. L. González et al., "Aberrant splicing of a mouse disabled homolog, mdab1, in the scrambler mouse," Neuron, vol. 19, no. 2, pp. 239-249, 1997.

[91] H. Yoneshima, E. Nagata, M. Matsumoto et al., "A novel neurological mutant mouse, yotari, which exhibits reeler-like phenotype but expresses CR-50 antigen/Reelin," Neuroscience Research, vol. 29, no. 3, pp. 217-223, 1997.

[92] B. W. Howell, R. Hawkes, P. Soriano, and J. A. Cooper, "Neuronal position in the developing brain is regulated by mouse disabled-1," Nature, vol. 389, no. 6652, pp. 733-737, 1997.

[93] B. A. Ballif, L. Arnaud, W. T. Arthur, D. Guris, A. Imamoto, and J. A. Cooper, "Activation of a Dab1/CrkL/C3G/Rapl pathway in Reelin-stimulated neurons," Current Biology, vol. 14, no. 7, pp. 606-610, 2004.

[94] B. W. Howell, T. M. Herrick, and J. A. Cooper, "Reelininduced tyrosine phosphorylation of disabled 1 during neuronal positioning," Genes and Development, vol. 13, no. 12, pp. 643648, 1999.

[95] L. Keshvara, D. Benhayon, S. Magdaleno, and T. Curran, "Identification of Reelin-induced sites of tyrosyl phosphorylation on disabled 1," Journal of Biological Chemistry, vol. 276, no. 19, pp. 16008-16014, 2001.

[96] L. Arnaud, B. A. Ballif, E. Förster, and J. A. Cooper, "Fyn tyrosine kinase is a critical regulator of disabled-1 during brain development," Current Biology, vol. 13, no. 1, pp. 9-17, 2003.

[97] H. H. Bock and J. Herz, "Reelin activates Src family tyrosine kinases in neurons," Current Biology, vol. 13, no. 1, pp. 18-26, 2003.

[98] B. W. Howell, T. M. Herrick, J. D. Hildebrand, Y. Zhang, and J. A. Cooper, "Dab1 tyrosine phosphorylation sites relay positional 
signals during mouse brain development," Current Biology, vol. 10, no. 15 , pp. 877-885, 2000.

[99] L. Arnaud, B. A. Ballif, and J. A. Cooper, "Regulation of protein tyrosine kinase signaling by substrate degradation during brain development," Molecular and Cellular Biology, vol. 23, no. 24, pp. 9293-9302, 2003.

[100] S. Suetsugu, T. Tezuka, T. Morimura et al., "Regulation of actin cytoskeleton by mDabl through N-WASP and ubiquitination of mDabl," Biochemical Journal, vol. 384, no. 1, pp. 1-8, 2004.

[101] G. Kuo, L. Arnaud, P. Kronstad-O’Brien, and J. A. Cooper, "Absence of Fyn and Src causes a Reeler-like phenotype," Journal of Neuroscience, vol. 25, no. 37, pp. 8578-8586, 2005.

[102] M. Trommsdorff, M. Gotthardt, T. Hiesberger et al., "Reeler/disabled-like disruption of neuronal migration in knockout mice lacking the VLDL receptor and ApoE receptor 2," Cell, vol. 97, no. 6, pp. 689-701, 1999.

[103] G. D’Arcangelo, "Reelin mouse mutants as models of cortical development disorders," Epilepsy and Behavior, vol. 8, no. 1, pp. 81-90, 2006.

[104] L. Feng and J. A. Cooper, "Dual functions of Dab1 during brain development," Molecular and Cellular Biology, vol. 29, no. 2, pp. 324-332, 2009.

[105] G. Kerjan and J. G. Gleeson, "A missed exit: Reelin sets in motion Dabl polyubiquitination to put the break on neuronal migration," Genes and Development, vol. 21, no. 22, pp. 28502854, 2007.

[106] S. Zhao and M. Frotscher, "Go or stop? Divergent roles of reelin in radial neuronal migration," Neuroscientist, vol. 16, no. 4, pp. 421-434, 2010.

[107] D. S. Rice, M. Sheldon, G. D’Arcangelo, K. Nakajima, D. Goldowitz, and T. Curran, "Disabled-1 acts downstream of Reelin in a signaling pathway that controls laminar organization in the mammalian brain," Development, vol. 125, no. 18, pp. 3719-3729, 1998.

[108] G. Meyer, C. L. De Rouvroit, A. M. Goffinet, and P. Wahle, "Disabled-1 mRNA and protein expression in developing human cortex," European Journal of Neuroscience, vol. 17, no. 3 , pp. 517-525, 2003.

[109] J. M. Luque, J. Morante-Oria, and A. Fairén, "Localization of ApoER2, VLDLR and Dab1 in radial glia: groundwork for a new model of reelin action during cortical development," Developmental Brain Research, vol. 140, no. 2, pp. 195-203, 2003.

[110] E. Hartfuss, E. Förster, H. H. Bock et al., "Reelin signaling directly affects radial glia morphology and biochemical maturation," Development, vol. 130, pp. 4597-4609, 2003.

[111] K. Sanada, A. Gupta, and L.-H. Tsai, "Disabled-1-regulated adhesion of migrating neurons to radial glial fiber contributes to neuronal positioning during early corticogenesis," Neuron, vol. 42, no. 2, pp. 197-211, 2004.

[112] R. M. Hoffarth, J. G. Johnston, L. A. Krushel, and D. Van der Kooy, "The mouse mutation reeler causes increased adhesion within a subpopulation of early postmitotic cortical neurons," Journal of Neuroscience, vol. 15, no. 7, pp. 4838-4850, 1995.

[113] S. J. Franco, I. Martinez-Garay, C. Gil-Sanz, S. R. HarkinsPerry, and U. Müller, "Reelin regulates cadherin function via Dab1/Rap1 to control neuronal migration and lamination in the neocortex," Neuron, vol. 69, no. 3, pp. 482-497, 2011.

[114] H. Tabata and K. Nakajima, "Efficient in utero gene transfer system to the developing mouse brain using electroporation: visualization of neuronal migration in the developing cortex," Neuroscience, vol. 103, no. 4, pp. 865-872, 2001.
[115] T. Miyata, Y. Ono, M. Okamoto et al., "Migration, early axonogenesis, and Reelin-dependent layer-forming behavior of early/posterior-born Purkinje cells in the developing mouse lateral cerebellum," Neural Development, vol. 5, no. 1, article 23, 2010.

[116] R. S. O’Dell, C. J. Ustine, D. A. Cameron et al., "Layer 6 cortical neurons require Reelin-Dabl signaling for cellular orientation, Golgi deployment, and directed neurite growth into the marginal zone," Neural Development, vol. 7, p. 25, 2012.

[117] K. Sekine, T. Kawauchi, K. Kubo et al., "Reelin controls neuronal positioning by promoting cell-matrix adhesion via inside-out activation of integrin $\alpha 5 \beta 1$," Neuron, vol. 76, pp. 353-369, 2012.

[118] C. Gil-Sanz, S. J. Franco, I. Martinez-Garay, A. Espinosa, S. Harkins-Perry, and U. Muller, "Cajal-Retzius cells instruct neuronal migration by coincidence signaling between secreted and contact-dependent guidance cues," Neuron, vol. 79, pp. 461477, 2013.

[119] Y. Jossin and J. A. Cooper, "Reelin, Rap1 and N-cadherin orient the migration of multipolar neurons in the developing neocortex," Nature Neuroscience, vol. 14, no. 6, pp. 697-703, 2011.

[120] B. A. Ballif, L. Arnaud, and J. A. Cooper, "Tyrosine phosphorylation of disabled-1 is essential for Reelin-stimulated activation of Akt and Src family kinases," Molecular Brain Research, vol. 117, no. 2, pp. 152-159, 2003.

[121] U. Beffert, G. Morfini, H. H. Bock, H. Reyna, S. T. Brady, and J. Herz, "Reelin-mediated signaling locally regulates protein kinase B/Akt and glycogen synthase kinase $3 \beta$," Journal of Biological Chemistry, vol. 277, no. 51, pp. 49958-49964, 2002.

[122] H. H. Bock, Y. Jossin, P. Liu et al., "Phosphatidylinositol 3kinase interacts with the adaptor protein Dabl in response to reelin signaling and is required for normal cortical lamination," Journal of Biological Chemistry, vol. 278, no. 40, pp. 3877238779, 2003.

[123] M. Laplante and D. M. Sabatini, "mTOR signaling at a glance," Journal of Cell Science, vol. 122, no. 20, pp. 3589-3594, 2009.

[124] D. D. Sarbassov, D. A. Guertin, S. M. Ali, and D. M. Sabatini, "Phosphorylation and regulation of Akt/PKB by the rictormTOR complex," Science, vol. 307, no. 5712, pp. 1098-1101, 2005.

[125] T. M. Kazdoba, C. N. Sunnen, B. Crowell, G. H. Lee, A. E. Anderson, and G. D’Arcangelo, "Development and characterization of NEX-Pten, a novel forebrain excitatory neuronspecific knockout mouse," Developmental Neuroscience, vol. 34, no. 2-3, pp. 198-209, 2012.

[126] C. B. Chan, X. Liu, S. Pradoldej et al., "Phosphoinositide 3kinase enhancer regulates neuronal dendritogenesis and survival in neocortex," Journal of Neuroscience, vol. 31, no. 22, pp. 8083-8092, 2011.

[127] J. Iafrati, M. J. Orejarena, O. Lassalle, L. Bouamrane, and P. Chavis, "Reelin, an extracellular matrix protein linked to early onset psychiatric diseases, drives postnatal development of the prefrontal cortex via GluN2B-NMDARs and the mTOR pathway," Molecular Psychiatry, 2013.

[128] J. Trotter, G. H. Lee, T. M. Kazdoba et al., "Dabl is required for synaptic plasticity and associative learning," The Journal of Neuroscience, vol. 33, pp. 15652-15668, 2013.

[129] S. Hirotsune, M. W. Fleck, M. J. Gambello et al., "Graded reduction of Pafahlb1 (Lis1) activity results in neuronal migration defects and early embryonic lethality," Nature Genetics, vol. 19, no. 4, pp. 333-339, 1998.

[130] M. Hattori, H. Adachi, M. Tsujimoto, H. Arai, and K. Inoue, "Miller-Dieker lissencephaly gene encodes a subunit of brain 
platelet-activating factor," Nature, vol. 370, no. 6486, pp. 216218, 1994.

[131] O. Reiner, R. Carrozzo, Y. Shen et al., "Isolation of a MillerDieker lissencephaly gene containing $\mathrm{G}$ protein $\beta$-subunit-like repeats," Nature, vol. 364, no. 6439, pp. 717-721, 1993.

[132] A. H. Assadi, G. Zhang, U. Beffert et al., "Interaction of reelin signaling and Lis1 in brain development," Nature Genetics, vol. 35, no. 3, pp. 270-276, 2003.

[133] A. H. Assadi, G. Zhang, R. McNeil, G. D. Clark, and G. D’Arcangelo, "Pafahlb2 mutations suppress the development of hydrocephalus in compound Pafahlb1; Reln and Pafahlb1; Dab1 mutant mice," Neuroscience Letters, vol. 439, no. 1, pp. 100-105, 2008.

[134] G. Zhang, A. H. Assadi, M. Roceri, G. D. Clark, and G. D'Arcangelo, "Differential interaction of the Pafahlb alpha subunits with the Reelin transducer Dabl," Brain Research, vol. 1267, pp. 1-8, 2009.

[135] L.-H. Tsai and J. G. Gleeson, "Nucleokinesis in neuronal migration," Neuron, vol. 46, no. 3, pp. 383-388, 2005.

[136] A. Pramatarova, P. G. Ochalski, K. Chen et al., "Nck $\beta$ interacts with tyrosine-phosphorylated disabled 1 and redistributes in Reelin-stimulated neurons," Molecular and Cellular Biology, vol. 23, no. 20, pp. 7210-7221, 2003.

[137] R. Homayouni, S. Magdaleno, L. Keshvara, D. S. Rice, and T. Curran, "Interaction of disabled-1 and the GTPase activating protein Dab2IP in mouse brain," Molecular Brain Research, vol. 115, no. 2, pp. 121-129, 2003.

[138] Y. Huang, S. Magdaleno, R. Hopkins, C. Slaughter, T. Curran, and L. Keshvara, "Tyrosine phosphorylated disabled 1 recruits Crk family adapter proteins," Biochemical and Biophysical Research Communications, vol. 318, no. 1, pp. 204-212, 2004.

[139] G. H. Lee, S. H. Kim, R. Homayouni, and G. D’Arcangelo, "Dab2ip regulates neuronal migration and neurite outgrowth in the developing neocortex," PLoS ONE, vol. 7, Article ID e46592, 2012.

[140] S. Qiao, S. H. Kim, D. Heck, D. Goldowitz, M. S. LeDoux, and R. Homayouni, "Dab2IP GTPase activating protein regulates dendrite development and synapse number in cerebellum," PLoS ONE, vol. 8, Article ID e53635, 2013.

[141] T.-J. Park and T. Curran, "Crk and Crk-like play essential overlapping roles downstream of disabled-1 in the reelin pathway," Journal of Neuroscience, vol. 28, no. 50, pp. 13551-13562, 2008.

[142] T. Hiesberger, M. Trommsdorff, B. W. Howell et al., "Direct binding of Reelin to VLDL receptor and ApoE receptor 2 induces tyrosine phosphorylation of disabled-1 and modulates tau phosphorylation," Neuron, vol. 24, no. 2, pp. 481-489, 1999.

[143] J. Herz, "The LDL receptor gene family: (Un)expected signal transducers in the brain," Neuron, vol. 29, no. 3, pp. 571-581, 2001.

[144] D. Benhayon, S. Magdaleno, and T. Curran, "Binding of purified Reelin to ApoER2 and VLDLR mediates tyrosine phosphorylation of disabled-1," Molecular Brain Research, vol. 112, no. 1-2, pp. 33-45, 2003.

[145] M. Trommsdorff, J.-P. Borg, B. Margolis, and J. Herz, "Interaction of cytosolic adaptor proteins with neuronal apolipoprotein E receptors and the amyloid precursor protein," Journal of Biological Chemistry, vol. 273, no. 50, pp. 33556-33560, 1998.

[146] T. Morimura, M. Hattori, M. Ogawa, and K. Mikoshiba, "Disabled1 regulates the intracellular trafficking of reelin receptors," Journal of Biological Chemistry, vol. 280, no. 17, pp. 16901-16908, 2005.
[147] V. Strasser, D. Fasching, C. Hauser et al., "Receptor clustering is involved in Reelin signaling," Molecular and Cellular Biology, vol. 24, no. 3, pp. 1378-1386, 2004.

[148] G. Zhang, A. H. Assadi, R. S. McNeil et al., "The Pafahlb complex interacts with the reelin receptor VLDLR," PLoS ONE, vol. 2, no. 2, article e252, 2007.

[149] U. Beffert, E. J. Weeber, A. Durudas et al., "Modulation of synaptic plasticity and memory by Reelin involves differential splicing of the lipoprotein receptor Apoer2," Neuron, vol. 47, no. 4, pp. 567-579, 2005.

[150] L. Dulabon, E. C. Olson, M. G. Taglienti et al., "Reelin binds $\alpha 3 \beta 1$ integrin and inhibits neuronal migration," Neuron, vol. 27, no. 1, pp. 33-44, 2000.

[151] D. Graus-Porta, S. Blaess, M. Senften et al., " $\beta 1$-Class integrins regulate the development of laminae and folia in the cerebral and cerebellar cortex," Neuron, vol. 31, no. 3, pp. 367-379, 2001.

[152] R. Belvindrah, D. Graus-Porta, S. Goebbels, K.-A. Nave, and U. Müller, " $\beta 1$ integrins in radial glia but not in migrating neurons are essential for the formation of cell layers in the cerebral cortex," Journal of Neuroscience, vol. 27, no. 50, pp. 13854-13865, 2007.

[153] E. Förster, A. Tielsch, B. Saum et al., "Reelin, disabled 1, and $\beta 1$ integrins are required for the formation of the radial glial scaffold in the hippocampus," Proceedings of the National Academy of Sciences of the United States of America, vol. 99, no. 20, pp. 13178-13183, 2002.

[154] K. Senzaki, M. Ogawa, and T. Yagi, "Proteins of the CNR family are multiple receptors for reelin," Cell, vol. 99, no. 6, pp. 635-647, 1999.

[155] A. Sentürk, S. Pfennig, A. Weiss, K. Burk, and A. Acker-Palmer, "Ephrin Bs are essential components of the Reelin pathway to regulate neuronal migration," Nature, vol. 472, no. 7343, pp. 356-360, 2011.

[156] T. Catchpole and M. Henkemeyer, "EphB2 tyrosine kinasedependent forward signaling in migration of neuronal progenitors that populate and form a distinct region of the dentate niche," Journal of Neuroscience, vol. 31, no. 32, pp. 11472-11483, 2011.

[157] E. Bouche, M. I. Romero-Ortega, M. Henkemeyer et al., "Reelin induces EphB activation," Cell Research, vol. 23, pp. 473-490, 2013.

[158] V. Villar-Cervino, M. Molano-Mazon, T. Catchpole et al., "Contact repulsion controls the dispersion and final distribution of Cajal-Retzius cells," Neuron, vol. 77, pp. 457-471, 2013.

[159] T. Matsuki, A. Pramatarova, and B. W. Howell, "Reduction of Crk and CrkL expression blocks reelin-induced dendritogenesis," Journal of Cell Science, vol. 121, no. 11, pp. 1869-1875, 2008.

[160] C. Stritt and B. Knöll, "Serum response factor regulates hippocampal lamination and dendrite development and is connected with reelin signaling," Molecular and Cellular Biology, vol. 30, no. 7, pp. 1828-1837, 2010.

[161] J. Leemhuis and H. H. Bock, "Reelin modulates cytoskeletal organization by regulating Rho GTPases," Communicative and Integrative Biology, vol. 4, no. 3, pp. 254-257, 2011.

[162] M. Meseke, G. Rosenberger, and E. Forster, "Reelin and the $\mathrm{Cdc} 42 / \mathrm{Racl}$ guanine nucleotide exchange factor alphaPIX/Arhgef6 promote dendritic Golgi translocation in hippocampal neurons," European Journal of Neuroscience, vol. 37, pp. 1404-1412, 2013.

[163] P. Chameau, D. Inta, T. Vitalis, H. Monyer, W. J. Wadman, and J. A. van Hooft, "The N-terminal region of reelin regulates 
postnatal dendritic maturation of cortical pyramidal neurons," Proceedings of the National Academy of Sciences of the United States of America, vol. 106, no. 17, pp. 7227-7232, 2009.

[164] H.-S. Hoe, J. L. Kea, R. S. E. Carney et al., "Interaction of Reelin with amyloid precursor protein promotes neurite outgrowth," Journal of Neuroscience, vol. 29, no. 23, pp. 7459-7473, 2009.

[165] H.-S. Hoe, T. S. Tran, Y. Matsuoka, B. W. Howell, and G. W. Rebeck, "DAB1 and reelin effects on amyloid precursor protein and ApoE receptor 2 trafficking and processing," Journal of Biological Chemistry, vol. 281, no. 46, pp. 35176-35185, 2006.

[166] J. H. Trotter, M. Klein, U. K. Jinwal et al., "ApoER2 function in the establishment and maintenance of retinal synaptic connectivity," Journal of Neuroscience, vol. 31, no. 40, pp. 14413-14423, 2011.

[167] S. Qiu, K. M. Korwek, A. R. Pratt-Davis, M. Peters, M. Y. Bergman, and E. J. Weeber, "Cognitive disruption and altered hippocampus synaptic function in Reelin haploinsufficient mice," Neurobiology of Learning and Memory, vol. 85, no. 3, pp. 228-242, 2006.

[168] P. Tueting, E. Costa, Y. Dwivedi et al., "The phenotypic characteristics of heterozygous reeler mouse," NeuroReport, vol. 10, no. 6, pp. 1329-1334, 1999.

[169] E. Costa, Y. Chen, J. Davis et al., "REELIN and schizophrenia: a disease at the interface of the genome and the epigenome," Molecular Interventions, vol. 2, no. 1, pp. 47-57, 2002.

[170] D. D. Krueger, J. L. Howell, B. F. Hebert, P. Olausson, J. R. Taylor, and A. C. Nairn, "Assessment of cognitive function in the heterozygous reeler mouse," Psychopharmacology, vol. 189, no. 1, pp. 95-104, 2006.

[171] W. S. Liu, C. Pesold, M. A. Rodriguez et al., "Down-regulation of dendritic spine and glutamic acid decarboxylase 67 expressions in the reelin haploinsufficient heterozygous reeler mouse," Proceedings of the National Academy of Sciences of the United States of America, vol. 98, no. 6, pp. 3477-3482, 2001.

[172] J. T. Rogers, L. Zhao, J. H. Trotter et al., "Reelin supplementation recovers sensorimotor gating, synaptic plasticity and associative learning deficits in the heterozygous reeler mouse," Journal of Psychopharmacology, vol. 27, pp. 386-395, 2013.

[173] J. T. Rogers, I. Rusiana, J. Trotter et al., "Reelin supplementation enhances cognitive ability, synaptic plasticity, and dendritic spine density," Learning and Memory, vol. 18, no. 9, pp. 558-564, 2011.

[174] M. A. Rodriguez, C. Pesold, W. S. Liu et al., "Colocalization of integrin receptors and reelin in dendritic spine postsynaptic densities of adult nonhuman primate cortex," Proceedings of the National Academy of Sciences of the United States of America, vol. 97, no. 7, pp. 3550-3555, 2000.

[175] L. A. Glantz and D. A. Lewis, "Decreased dendritic spine density on prefrontal cortical pyramidal neurons in schizophrenia," Archives of General Psychiatry, vol. 57, no. 1, pp. 65-73, 2000.

[176] J. L. Brigman, K. E. Padukiewicz, M. L. Sutherland, and L. A. Rothblat, "Executive functions in the heterozygous reeler mouse model of schizophrenia," Behavioral Neuroscience, vol. 120, no. 4, pp. 984-988, 2006.

[177] A. M. Barr, K. N. Fish, A. Markou, and W. G. Honer, "Heterozygous reeler mice exhibit alterations in sensorimotor gating but not presynaptic proteins," European Journal of Neuroscience, vol. 27, no. 10, pp. 2568-2574, 2008.

[178] V. Martínez-Cerdeño, M. J. Galazo, C. Cavada, and F. Clasca, "Reelin immunoreactivity in the adult primate brain: intracellular localization in projecting and local circuit neurons of the cerebral cortex, hippocampus and subcortical regions," Cerebral Cortex, vol. 12, no. 12, pp. 1298-1311, 2002.

[179] C. Pesold, W. S. Liu, A. Guidotti, E. Costa, and H. J. Caruncho, "Cortical bitufted, horizontal, and Martinotti cells preferentially express and secrete reelin into perineuronal nets, nonsynaptically modulating gene expression," Proceedings of the National Academy of Sciences of the United States of America, vol. 96, no. 6, pp. 3217-3222, 1999.

[180] R. C. Roberts, L. Xu, J. K. Roche, and B. Kirkpatrick, "Ultrastructural localization of reelin in the cortex in post-mortem human brain," Journal of Comparative Neurology, vol. 482, no. 3, pp. 294-308, 2005.

[181] E. J. Weeber, U. Beffert, C. Jones et al., "Reelin and apoE receptors cooperate to enhance hippocampal synaptic plasticity and learning," Journal of Biological Chemistry, vol. 277, no. 42, pp. 39944-39952, 2002.

[182] C. G. Campo, M. Sinagra, D. Verrier, O. J. Manzoni, and P. Chavis, "Reelin secreted by GABAergic neurons regulates glutamate receptor homeostasis," PloS ONE, vol. 4, no. 5, Article ID e5505, 2009.

[183] Y. Chen, U. Beffert, M. Ertunc et al., "Reelin modulates NMDA receptor activity in cortical neurons," Journal of Neuroscience, vol. 25, no. 36, pp. 8209-8216, 2005.

[184] L. Groc, D. Choquet, F. A. Stephenson, D. Verrier, O. J. Manzoni, and P. Chavis, "NMDA receptor surface trafficking and synaptic subunit composition are developmentally regulated by the extracellular matrix protein reelin," Journal of Neuroscience, vol. 27, no. 38, pp. 10165-10175, 2007.

[185] S. Qiu and E. J. Weeber, "Reelin signaling facilitates maturation of CA1 glutamatergic synapses," Journal of Neurophysiology, vol. 97, no. 3, pp. 2312-2321, 2007.

[186] S. Qiu, L. F. Zhao, K. M. Korwek, and E. J. Weeber, "Differential reelin-induced enhancement of NMDA and AMPA receptor activity in the adult hippocampus," Journal of Neuroscience, vol. 26, no. 50, pp. 12943-12955, 2006.

[187] S. Hellwig, I. Hack, J. Kowalski et al., "Role for reelin in neurotransmitter release," Journal of Neuroscience, vol. 31, no. 7, pp. 2352-2360, 2011.

[188] I. Knuesel, "Reelin-mediated signaling in neuropsychiatric and neurodegenerative diseases," Progress in Neurobiology, vol. 91, no. 4, pp. 257-274, 2010. 

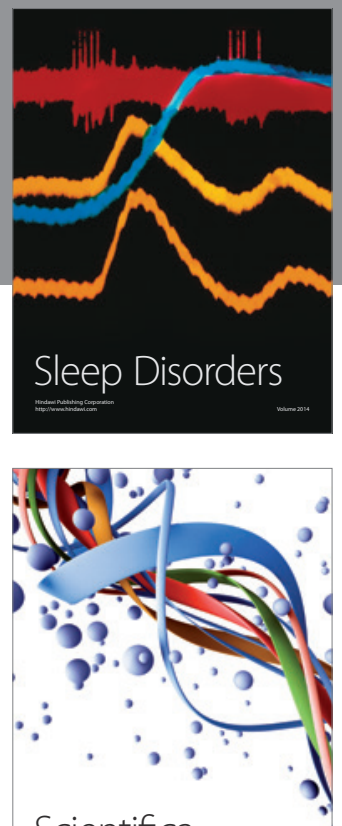

Scientifica
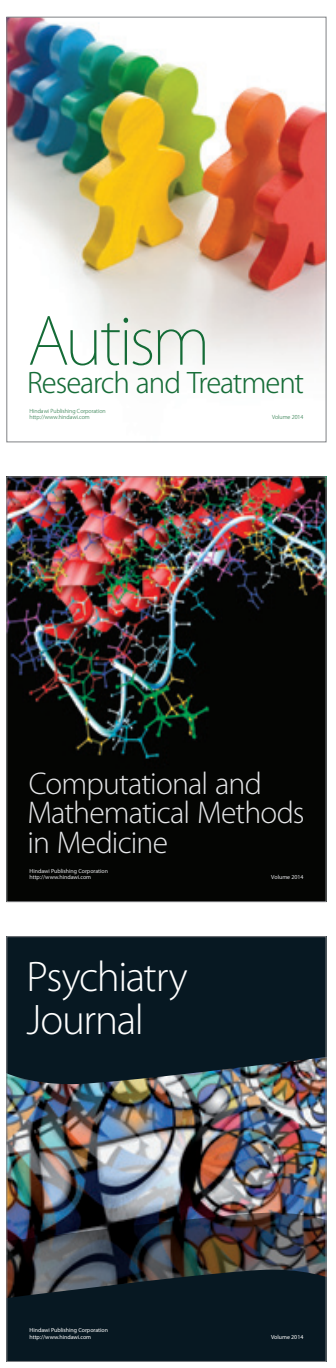
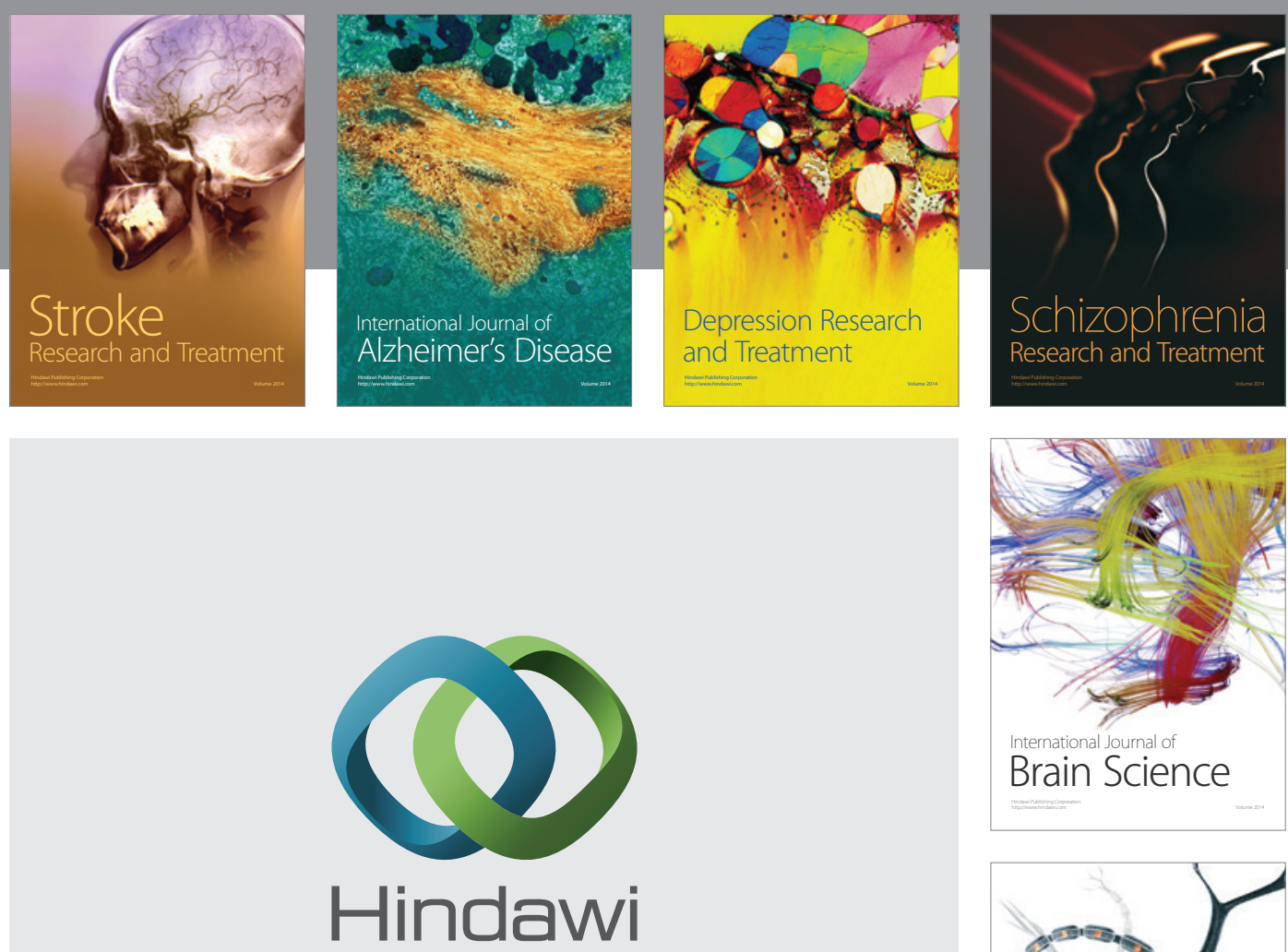

Submit your manuscripts at

http://www.hindawi.com
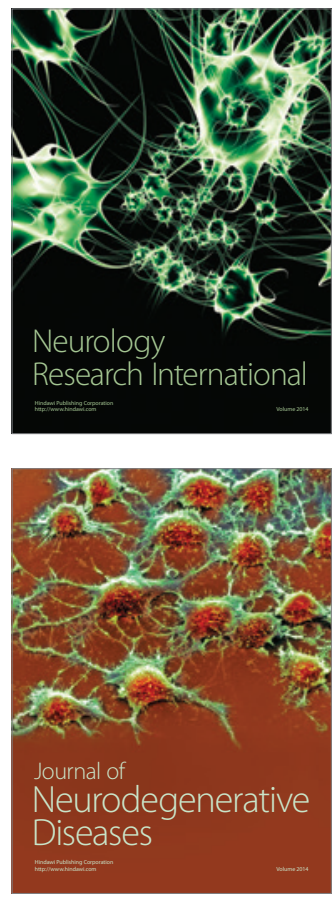

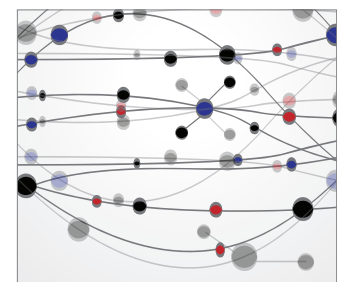

The Scientific World Journal
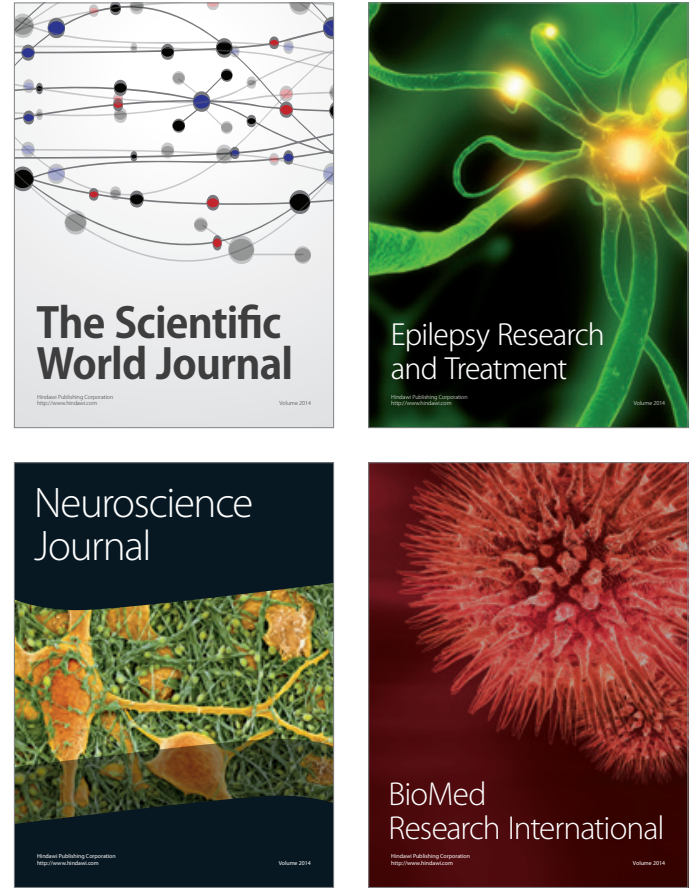

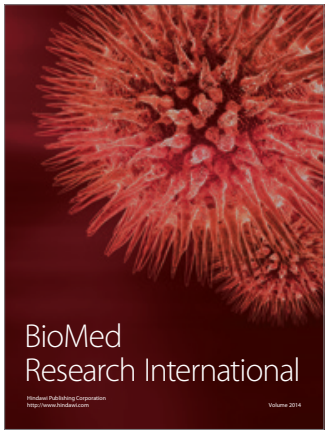

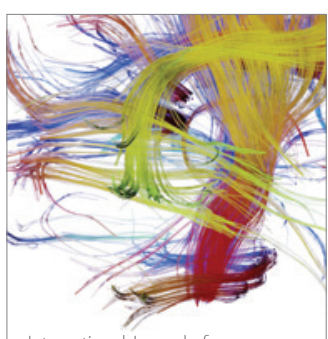

Brain Science

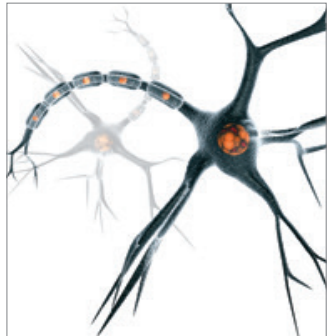

Neural Plasticity
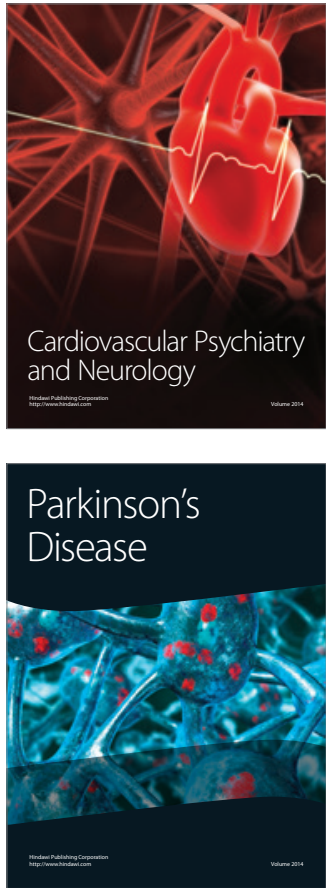